\title{
Endogenous enforcement of intellectual property, North-South trade, and growth
}

\section{Journal Article}

Author(s):

Schäfer, Andreas; Schneider, Maik T.

Publication date:

2015-07

Permanent link:

https://doi.org/10.3929/ethz-b-000096361

Rights / license:

In Copyright - Non-Commercial Use Permitted

Originally published in:

Macroeconomic Dynamics 19(5), https://doi.org/10.1017/S1365100513000709 


\title{
ENDOGENOUS ENFORCEMENT OF INTELLECTUAL PROPERTY, NORTH-SOUTH TRADE, AND GROWTH
}

\author{
ANDREAS SCHÄFER \\ University of Leipzig \\ MAIK T. SCHNEIDER \\ CER-ETH Center of Economic Research, ETH Zurich
}

\begin{abstract}
Now that most countries have harmonized intellectual property right (IPR) legislation as a consequence of signing the Agreement on Trade-Related Aspects of Intellectual Property Rights (TRIPs), the dispute about the optimal level of IPR protection has shifted toward IPR enforcement. This paper develops an endogenous growth framework with two open economies satisfying the classical North-South assumptions to study (a) the regions' incentives to enforce IPRs in a decentralized game, (b) the desired IPR enforcement of the two regions in negotiation rounds on global harmonization, and (c) the constrained efficient enforcement level. We show how the different solutions relate to each other and how the results depend on the research productivity in the North and the regions' relative market sizes. Although growth rates increase substantially when IPR enforcement is harmonized at the North's desired level, our numerical simulation suggests that the South may also benefit in terms of long-run welfare.
\end{abstract}

Keywords: Endogenous Growth, Intellectual Property Rights, Trade, Dynamic Game

\section{INTRODUCTION}

As trade in knowledge-intensive goods accelerated during the last decades, patent and copyright infringements became a problem of the highest concern. Although the Agreement on Trade-Related Aspects of Intellectual Property Rights (TRIPs) specifies a minimum set of protection standards that members of the World Trade Organization (WTO) have to assent to, the enforcement of intellectual property rights (IPRs) is still subject to great international heterogeneity and further fuels the debate about the optimal protection level of IPRs in the world. 
For example, the European Commission's IPR Enforcement Report 2009 gives account of serious problems with IPR enforcement in a large number of mostly developing countries. Complaints include injunctions or criminal sanctions often being difficult to obtain and civil procedures being lengthy and burdensome with high uncertainty of outcomes. Involved staff is insufficiently trained and lacks resources to effectively prosecute and convict violators, and cooperation between authorities is insufficient. For some countries the report even assesses a lack of political will indicated by their opposing in-depth enforcement discussions in international fora such as the WTO or the WIPO. ${ }^{1}$

Studying the distributional effects of TRIPs, McCalman (2001) argues that the agreement involves transfers from developing countries to developed countries due to stronger IPR protection. These transfers are primarily determined by enforcement efforts rather than the extension of the coverage of patent protection. Thus, he reasons that the developing countries "will be more willing to extend the coverage of patent protection as required by TRIPs, but may be less willing to devote adequate resources to enforcement." Further, he predicted that "future North-South tensions over intellectual property rights are likely to be centered around enforcement issues rather than the sectoral coverage of protection offered" [McCalman (2001, p. 181)]. ${ }^{2}$

The recent debate on the Anti-Counterfeiting Trade Agreement (ACTA) also indicates that questions on IPR enforcement are among the most fiercely discussed living causes. ${ }^{3}$ ACTA was worked out in secret negotiations with the aim of harmonizing international standards of IPR enforcement. ${ }^{4}$ An agreement was reached in April 2011 between several countries, among them the United States and the members of the European Union. ${ }^{5}$ An ultimate objective of ACTA is that large emerging economies, "where IPRs could be improved will sign up to the global pact" [EU Commission (2008); Reuters (2010)]. ${ }^{6}$ However, the European Parliament voted against ACTA on July 4, 2012, thereby opposing the European Commission, which will now seek the legal opinion of the European Court of Justice and approach the European Parliament to find an agreement in the future. ${ }^{7}$

Inspired by these recent developments, this paper develops an endogenous growth framework for studying IPR enforcement within the context of a classical North-South trade model. Our analysis is characterized by the following features, which distinguish our paper from the previous literature. First, we assume equal strength of enforcement of all active patents in a region at any point in time. Second, a government cannot commit to IPR enforcement for the indefinite future, but after each legislative term, the (new) government may adjust its enforcement efforts as it sees fit. Third, when it sets its policies, the government's planning horizon is limited.

By the first two assumptions, we intend to capture important aspects of IPR enforcement. With regard to the first item, we argue that in reality IPR enforcement depends on whether or not a patent is active, ruling out the possibility that IPR enforcement distinguishes active patents by, e.g., the year of invention. ${ }^{8}$ Second, although formal law may be fixed for substantial time horizons, the enforcement 
of laws can be changed more easily-for example, by reallocating resources used for IPR enforcement to other purposes. Our third assumption reflects an important aspect of policy making in that governments are not or not only motivated by fostering long-term welfare but also are concerned with political ends. ${ }^{9}$

Incorporating these assumptions into a dynamic model with endogenous innovation arguably makes the analysis of IPR enforcement more realistic. However, it is also particularly interesting because it adds another area of tension resulting from the different planning horizons of the governments and the innovators. At the heart of our analysis is the governments' classic trade-off between static efficiency and dynamic gains extended by international externalities of IPR protection with regard to R\&D incentives and profit flows. ${ }^{10}$ By choosing IPR enforcement, the government has to trade off welfare today-by incurring deadweight losses and $R \& D$ costs - against future welfare resulting from a higher technological level. Without internalizing the full future benefits of innovations, an office-termmotivated government may be more reluctant to bear the costs of great innovative activity that impose a substantial burden on current welfare.

As a consequence, we find that in the decentralized equilibrium of the IPR enforcement game between the North and the South, the relation between the North's equilibrium IPR enforcement level and its own research productivity exhibits an inverted U-shape. When the research capacity is low, the dynamic gains of IPR enforcement dominate and the enforcement level increases with higher productivity of research. However, if the research capacity is very high, the farsighted firms' R\&D investments and the deadweight losses are very large, reducing current consumption and welfare levels. This can lead a short-sighted Northern government to reduce IPR enforcement in response to even higher research productivity. As the South does not engage in $R \& D$, it neglects research expenditures but considers its influence on the R\&D activity in the North. Accordingly, the South's equilibrium IPR enforcement increases monotonically with the North's innovative capacity. Hence, the office-motivated government in the North possesses higher incentives to enforce IPRs than the one in the South when the North's R\&D productivity is low, whereas the opposite may be the case for very high levels of R\&D productivity. Further, we find that a country's relative market size positively affects its equilibrium IPR enforcement level. The intuition is that a larger country's impact on $R \& D$ incentives is relatively high and therefore its incentive to free ride on the other region's IPR efforts is lower.

By analyzing the regions' preferred harmonized IPR enforcement levels on a global scale, we seek to shed light on potential clashes of interest in international negotiation rounds. We compare the preferred harmonized enforcement levels with those chosen in the decentralized equilibrium and relate both to the constrained efficient solution reflecting the maximum welfare the two governments can achieve, given they are not able to escape their political economy constraints.

Both the North's and the South's desired harmonized IPR enforcement levels are higher than their respective equilibrium choices. Whereas the South's preferred harmonized enforcement level is independent of relative market sizes, the preferred 
level of the North typically exhibits a declining relationship with its relative market size. The reason is that a larger relative market size of the North involves relatively lower profit inflows from the South and higher deadweight losses in the North. This contrasts with the decentralized equilibrium where the North's equilibrium IPR enforcement level is positively associated with its relative market size. This result suggests that small innovative countries show large differences between their desired harmonized levels supported in negotiation rounds concerning global IPR enforcement and their own equilibrium choices.

Further, we find that relative to the constrained efficient solution, the regions' IPR enforcement levels in the decentralized equilibrium are too low. In contrast, the North's desired harmonized enforcement level is typically higher than the constrained efficient one, whereas that of the South is lower. As a consequence, the regions' growth rate is highest when the harmonized IPR enforcement level of the North is implemented. Would this rate of growth come at the expense of welfare in the South? A numerical illustration suggests that the South may well gain in terms of aggregate long-run welfare from adopting the North's desired harmonized IPR enforcement level, given a sufficiently productive R\&D sector in the North. However, the opposite holds for low research capacities in the North.

The literature has approached questions regarding the international protection of IPR from two perspectives: On one hand, from a macroeconomic endogenousgrowth perspective that treats the regions' IPR enforcement as exogenous and examines its effects on the resulting growth rate and on welfare [Helpman (1993); Lai (1998); Kwan and Lai (2003); Iwaisako et al. (2011)], and, on the other hand, from a rather microeconomic industrial-organization perspective that explicitly takes IPR enforcement as endogenous, but precludes long-run dynamics [Chin and Grossman (1990); Maskus (1990); Diwan and Rodrik (1991); Deardorff (1992); Lai and Qiu (2003)].

This paper establishes a dynamic general equilibrium framework and considers endogenous choices of IPRs and their welfare implications.

In the next section, we relate our paper to the literature in more detail. We introduce the model in Section 3. We examine the noncooperative game in which both regions choose their national IPR enforcement decentrally in Section 4. In Section 5, we analyze the preferred harmonized enforcement levels of the North and the South. Section 6 compares the desired harmonized enforcement levels and the decentralized equilibrium with the constrained efficient solution. We present implications for welfare in Section 7 and provide a summary and conclusions in Section 8.

\section{RELATION TO THE LITERATURE}

A seminal work in the literature on international IPR protection is Grossman and Lai (2004), which also employs a framework of variety-expanding innovations, but considers a one-shot game with respect to IPR protection and does not allow for endogenous long-run economic growth. The equilibrium in Grossman and 
Lai (2004) can be interpreted as a subgame-perfect Nash equilibrium, where governments are able (1) to decide on the IPR protection level of each vintage of inventions separately and (2) to fully commit to it in the future. ${ }^{11}$ Such a setup implies the theoretical possibility that at a particular point in time, all different vintages of active patents enjoy different levels of IPR enforcement. This is precluded in our model. ${ }^{12}$ Grossman and Lai (2004) find that higher research capacity and larger market size are associated with higher IPR protection in the noncooperative game. Because of limited commitment possibilities for the governments, our model predicts a positive relation between research capacity and IPR enforcement for moderate research productivity levels. However, this relation may become negative for high levels of research capacity. Moreover, our model makes it possible to draw inferences on the effect of IPR enforcement on economic growth showing that even though IPR enforcement exhibits an inverted U-shape in the North's research capabilities, the rate of economic growth will strictly increase with research productivity. In contrast to Grossman and Lai (2004), we also shed light on distributional effects associated with harmonized IPR protection by deriving the countries' desired globally harmonized enforcement level. We find a negative effect of the North's relative market size on its preferred harmonized IPR enforcement, but a positive effect of its relative market size on the North's equilibrium enforcement level. This may explain tough international negotiation rounds as particularly small innovative countries advocate drastic IPR enforcement far from their equilibrium enforcement levels.

Scotchmer (2004a, Ch. 11; 2004b) provides an elegant reduced-form model where governments decide on the length of IPR protection. She does not derive the value of an innovation and the deadweight losses from an equilibrium analysis but takes them as exogenously given to focus entirely on the one-shot game of the governments when they set the patent length. Next to the Nash equilibrium, she also discusses the countries' desired harmonized IPR protection and finds that, given equal market sizes, the country with the higher research capacity desires higher globally harmonized IPR protection. Given equal productivity of R\&D, the smaller country prefers a longer globally harmonized patent length than the larger country. In contrast, our paper develops a full-fledged general equilibrium endogenous growth model and characterizes the entire comparative statics with respect to market size and the North's innovative capability. Taking a dynamic perspective and accounting for political economy constraints shows that results may reverse if the research capabilities of the North are very high.

Grinols and Lin (2006) offer one of the few dynamic models with endogenous IPRs. Particular to their setting is that they consider goods that are only demanded in the South but are invented in the North. In a numerical equilibrium analysis, they find that the South may well choose a higher level of IPR protection for this special set of products than the level of IPR protection chosen by the North for the remaining products, which are demanded in both regions. The driving force of this result is that the South cannot free-ride on IPR protection in the North to provide incentives for innovation in this particular product category. In the decentralized 
equilibrium in our model, it can also occur that the South enforces IPR more than the North if the innovative capacity of the North is sufficiently high. However, this result originates from politicoeconomic reasons rather than different demand structures in the North and the South.

The paper by Chen and Puttitanun (2005) derives the optimal level of IPR protection in a developing country depending on the country's relative strength in imitating and innovating products. By varying the relative imitation capabilities, they argue that IPR protection in developing countries can have a U-shaped form over the course of development; in particular, IPR protection increases when the country's own innovative capacities increase. Their paper offers an alternative view on IPR protection in developing countries by abstracting from strategic interaction with a developed country, which is at the heart of our model setup and results.

An intriguing paper by Eicher and Garcia-Penalosa (2008) takes a complementary approach to endogenizing the strength of IPR enforcement in an endogenous growth model of a closed economy. Rather than being a policy instrument of the government, IPR enforcement is the result of private investments by firms. This leads to multiple equilibria [one with high (low) IPR enforcement and high (low) R\&D investments], as investments in IPR protection and investments in R\&D are complements.

Important precursors of our work within the family of endogenous growth frameworks with exogenous IPRs are Helpman (1993), Lai (1998), and Iwaisako et al. (2011). However, in contrast to these papers, we emphasize IPR enforcement, which we model as the probability that a potential competitor that has reverse engineered the product is deterred from illegally entering the market. Helpman (1993) and Lai (1998) assume that once a product has been reverse engineered, unlawful competition cannot be prevented. These papers equate IPR protection with the probability that the product will be imitated, whereas we model IPR enforcement as the probability of effectively preventing commercial use of the reverse-engineered product. Helpman (1993) also considers a North-South setup where only the North innovates. IPRs are varied exogenously by changing the exogenously given imitation rate. Considering both trade and FDI, the extent of the latter plays a major role in determining the consequences of stricter IPR protection. ${ }^{13}$ Related to Helpman (1993), Lai (1998) considers multinational Northern firms that transfer the production of new products via FDI to the South and shows that the effects of IPR protection in the South depend crucially on whether imitation or FDI by multinational firms is the channel of international production transfer from the North to the South. ${ }^{14}$ A recent contribution by Iwaisako et al. (2011) uses the breadth of a patent as a measure of the strength of IPR protection. The paper conducts a welfare analysis in a North-South endogenous growth framework with quality-improving innovations and FDI. They find that the dynamic gains from enhanced innovations are sufficiently strong and that the South would even benefit by adopting the IPR standards of the North. As noted in the Introduction, in contrast to these papers, our model considers endogenous choices by governments, allowing us to derive results on the equilibrium behavior of countries concerning IPR enforcement and 
compare it with the constrained efficient and desired harmonized solutions of the different regions. ${ }^{15}$

Other, seminal contributions to the literature approached questions regarding the international protection of IPRs from an industrial organization perspective. In contrast to our paper, they typically take a partial equilibrium perspective and abstract from long-run dynamics. ${ }^{16}$ In this branch of the literature, Lai and Qiu (2003) is most closely related to our paper. They propose a static multisectoral North-South trade model, where both regions innovate and national governments set patent length. In their partial equilibrium analysis, they find that the countries' equilibrium patent length increases with relative market size. We argue that this is not always the case in a dynamic model incorporating political economy constraints and that the effect of relative market size on the desired harmonized IPR enforcement of regions is typically opposite to its effect on equilibrium IPR enforcement.

An important assumption in our model is the link between IPR protection and innovative activity. We employ the standard view that better enforcement of IPRs leads to higher R\&D expenditures. Recent empirical support for this assumption is provided by Branstetter et al. (2006). However, there is also a literature that doubts the positive effect of better IPR protection on higher research activity. For example, Sakakibara and Branstetter (2001) find no significant effect of the Japanese patent reforms of 1988 on innovative activity. An excellent recent overview of empirical studies on the link between IPR protection and innovative activity can be found in Maskus (2012), with most studies pointing toward a positive relation. ${ }^{17}$ Our theoretical model can accommodate both cases. In our setting, a country's innovative capacity is reflected by a R\&D cost parameter. High innovative capacity implies substantial reaction of innovative activity to a change in IPR enforcement, which would reflect the evidence found by Branstetter et al. (2006). In contrast, low innovative capacity would result in little additional R\&D in response to higher IPR enforcement, possibly because of costs associated with blocking patents. This would reflect the findings of Sakakibara and Branstetter (2001). However, if innovation remains constant or is even reduced in response to stronger IPR enforcement, governments will choose optimally an IPR enforcement level of zero in our framework. ${ }^{18}$

\section{THE MODEL}

We consider two regions, $n$ and $s$, that differ with respect to their innovative capacity. Region $n$, which we also refer to as the North, produces blueprints, which are licensed out to Region $s$, the South. For simplicity, we assume that there is no innovation activity in Region $s .{ }^{19}$ Our analysis builds on a variety-expandinggrowth framework in which at time $t$ a patent is enforced with probability $\omega_{j, t}$ in Region $j=s, n$. For simplicity, we assume that imitation is costless. Thus, if the patent is not enforced in period $t$, an imitated intermediate good is supplied under full competition and operating profits are zero. Our modeling strategy 
reflects our focus on IPR enforcement. As mentioned in Section 2, we emphasize the importance of prosecuting patent infringements, which contrasts with earlier papers by Helpman (1993) and Lai (1998). They assume that once a product has been reverse engineered the competitor can violate laws on IPR protection without consequences. Taken at face value, our setup includes the possibility that a patent is fully protected in periods $t$ and $t+2$ but protection is not enforced in $t+1$. A patent holder may produce the same (monopolistic) quantity of the intermediate product in each period, but can only charge the monopoly price in the periods in which IPR enforcement is perfect. In the period without enforcement of IPRs, other competitors are not effectively deterred from offering the intermediate good as well (after reverse- engineering it), thereby driving down prices to marginal costs. A broader interpretation is that different degrees of IPR enforcement constrain the degree of competition from violators of IPRs, thereby determining the (oligopolistic) prices that the patent holders are able to charge. Then the strength of IPR enforcement $\omega_{j, t}$ reflects the share of the monopoly profits that can be captured in period $t$ in country $j .^{20}$

Both economies are populated by a measure $L_{j}$ of households, each inelastically supplying one unit of labor in each period. There is no population growth and time moves in discrete steps $t=0,1,2, \ldots, \infty$. We set up a dynamic model for two reasons: First, our aim is to examine the consequences of endogenous IPR enforcement for economic growth and long-run welfare, which has not been done in the previous literature on endogenous enforcement of IPRs. Second, we are interested in the effects of the mismatch of time horizons between a politically motivated short-sighted government and innovators with long-term planning horizons. ${ }^{21}$ In the following, we first introduce the model for given levels of IPR enforcement in both regions and then discuss the governments' problems concerning their IPR enforcement choices.

\subsection{Production}

In Region $j$, the final good $Y_{j}$ is produced according to

$$
Y_{j}=A_{j} L_{j}^{1-\alpha} \int_{0}^{N_{t}}\left[x_{j t}(i)\right]^{\alpha} d i,
$$

where $A_{j}$ represents a productivity measure, $L_{j}$ is labor input, $N_{t}$ is the measure of different intermediates invented in the North at time $t$, and $x_{j t}(i)$ stands for the amount of intermediate $i$ used in final-good production in Region $j=n, s$ in period $t$. The elasticity of substitution between the different intermediates is determined by $\alpha \in(0,1)$.

Each intermediate good $i$ is produced by a monopolist or an imitator. The production of one unit of intermediate $i$ requires one unit of the final output. We choose final output as the numeraire. Hence marginal production costs of intermediates are equal to unity. The symmetric equilibrium in the market for 
intermediates induces equal prices and demand for all types of intermediates, such that $p_{m, j}(i)=p_{m, j}=1 / \alpha, x_{m, j}(i)=x_{m, j}$ for all protected intermediates, and $p_{c, j}(i)=p_{c, j}=1, x_{c, j}(i)=x_{c, j}$ for all imitated intermediates. Demand in

Region $j$ for protected intermediates is $x_{m, j}=\lambda_{j} \alpha^{2 /(1-\alpha)}$, with $\lambda_{j}=L_{j} A_{j}^{1 /(1-\alpha)}$ reflecting the "effective" market size of Region $j$. Hence, a small economy in terms of population may constitute a large effective market when its productivity level in final-good production is sufficiently high, and vice versa. Patent holders located in the North can attain operating profits per period $\pi=P\left(\lambda_{s}+\lambda_{n}\right)$ with $P=\left(\frac{1-\alpha}{\alpha}\right) \alpha^{2 /(1-\alpha)}>0$. If an intermediate is copied and IPRs are not enforced, it will be sold at the competitive price $p_{c, j}=1$. Then demand increases to $x_{c, j}=\lambda_{j} \alpha^{1 /(1-\alpha)}$, and operating profits in $j$ at time $t$ are zero.

Given the enforcement level $0 \leq \omega_{j, t} \leq 1$, the number of protected intermediates at time $t$ is $\omega_{j, t} \times N_{t}$, whereas $\left(1-\omega_{j, t}\right) \times N_{t}$ of the intermediates are imitated. Aggregate output in Region $j$ is therefore

$$
Y_{j, t}=\lambda_{j}^{1-\alpha}\left\{\int_{0}^{\omega_{j, t} N_{t}}\left[x_{m, j}(i)\right]^{\alpha} d i+\int_{0}^{\left(1-\omega_{j, t}\right) N_{t}}\left[x_{c, j}(i)\right]^{\alpha} d i\right\} .
$$

Additionally, assuming that $x_{m, j}=\alpha^{1 /(1-\alpha)} x_{c, j}$, we obtain $Y_{j, t}=\lambda_{j} N_{t}[1+$ $\left.\omega_{j, t}\left(\alpha^{\alpha /(1-\alpha)}-1\right)\right] x_{c, j}^{\alpha}$, where $\omega_{j, t}\left(\alpha^{\alpha /(1-\alpha)}-1\right)<0$ represents the deadweight loss due to monopolistic competition. ${ }^{22}$

\subsection{Research and Development}

The North performs R\&D in search of new designs (blueprints) for intermediate goods. Here, we use a lab equipment specification assuming that final output (which incorporates both labor and intermediate goods) enters as the main factor of production into the R\&D process. A measure $L_{n}^{e} \ll L_{n}$ of the population in the North have the entrepreneurial skills to operate a research lab. Each research lab operates under the cost function

$$
\zeta\left(\eta_{t}\right)=\frac{\delta \eta_{t}^{2}}{N_{t} / L_{n}^{e}}
$$

where $\eta_{t}$ denotes the number of new inventions at time $t$ and $\delta$ reflects the research productivity or the quality of the research infrastructure. Alternatively, $\delta$ can be interpreted as a measure of the entrepreneurs' human capital. That is, the higher the level of human capital, the lower $\delta$, implying that lab equipment can be used more productively. In addition, R\&D is positively affected by the entrepreneurs' average level of technological knowledge $N_{t} / L_{n}^{e}{ }^{23}$

A new blueprint invented in period $t$ can be employed in final-good production from $t+1$ on, and it receives a patent of infinite length. Accordingly, the expected 
value of an invention $i$ at time $t$ is

$$
E_{t}[V(i)]=\sum_{\tau=t+1}^{\infty}\left(\prod_{\hat{\tau}=t+1}^{\tau} \frac{1}{1+r_{\hat{\tau}}}\right) P\left(\lambda_{n} \omega_{n, \tau}+\lambda_{s} \omega_{s, \tau}\right)
$$

where $r_{t}$ is the interest rate in period $t$.

As $E_{t}[V(i)]$ is the same for all $i$, we will use the abbreviation $E_{t}$ in the following. Optimality requires that marginal costs for an additional invention equal its expected value. Consequently, inventions per research lab are given by

$$
\eta_{t}=E_{t} \frac{N_{t}}{2 \delta L_{n}^{e}}
$$

and the aggregate stock of technological knowledge evolves according to

$$
N_{t+1}-N_{t}=\eta_{t} L_{n}^{e}=E_{t} \frac{N_{t}}{2 \delta}
$$

Obviously, an increase in effective market size increases expected profits and therefore encourages innovations. ${ }^{24}$

\subsection{The Household's and the Government's Problem}

Concentrating on the governments' IPR enforcement decisions, we keep the individual household's problem deliberately simple. The households in Region $j$ maximize

$$
U_{j, t}=\sum_{\tau=t}^{\infty} \beta^{\tau-t} c_{j, \tau}
$$

where $0<\beta<1$ is the discount factor and $\frac{1-\beta}{\beta}$ is the rate of time preference, which, at equilibrium, must be equal to the interest rate, such that $\beta=\frac{1}{1+r_{t}}$ for all $t .^{25}$ For the entrepreneurs in the North, the maximization problem reduces to the decision of how much of their income (labor income plus the profit flows from their active patents) to invest in $\mathrm{R} \& \mathrm{D}$ and how much to consume in each period. This problem is solved by (5). The households in the North without entrepreneurial skills, as well as the households in the South, consume their labor income in each period.

As motivated in the Introduction, we intend to examine the effects of politically motivated short-sighted governments that do not fully take into account the longrun consequences of their actions. The simplest way to incorporate this aspect into our model is to assume that at any time $t$ the governments in both regions choose an optimal enforcement level of IPR to maximize ${ }^{26}$

$$
W_{j, t}=\sum_{\tau=t}^{t+1} \beta^{\tau-t} C_{j, \tau}
$$


subject to (6). $C_{j, t}$ stands for aggregate consumption in country $j$ at time $t$. As mentioned in the Introduction, we make two additional assumptions concerning the governments' IPR enforcement choices. First, governments can only commit to a level of IPR enforcement for the subsequent period, i.e., $\omega_{j, t+1}$, but not for the indefinite future. For example, while in office at time $t$, the government can increase training efforts of staff responsible for the prosecution and conviction of imitators of protected intermediates. A larger number of trained officials will then be available in $t+1$ to enforce the laws on IPRs. Similar arguments apply with respect to other resources or capacity building necessary for effective enforcement. ${ }^{27}$ Second, we assume that the enforcement level chosen by the government in Region $j$ applies to all active patents in the same way.

In a typical period $t$, the sequence of events can be summarized as follows. First, intermediate-good production and final-good production take place given the technology stock $N_{t}$ and IPR enforcement level $\omega_{j, t}$. Then, the government announces the level of IPR enforcement $\omega_{j, t+1}$ and thereafter the entrepreneurs decide how much to invest in R\&D. Finally, the households consume.

At any time $t$, aggregate consumption in the North, as well as the dynamics of the technology stock (6), depend on the R\&D expenditures in $t$, which reflect the entrepreneurs' expectations about future IPR enforcement beyond $t+1$. Let us denote these expectations at time $t$ by $\Omega_{t+2}^{\prime} \equiv\left\{\omega_{n, \tau}^{\prime}, \omega_{s, \tau}^{\prime}\right\}_{\tau=t+2}^{\infty}$ and the vector of IPR enforcement that will finally realize by $\Omega_{t+2}$. When deciding on IPR enforcement, $\omega_{j, t+1}$, the governments have expectations about the entrepreneurs' expectations $\Omega_{t+2}^{\prime}$, which we refer to as $\Omega_{t+2}^{g}$, and about how the entrepreneurs adapt their expectations in response to the governments' enforcement choices for period $t+1, \omega_{j, t+1}$. Even under the assumption of rational expectations, this structure allows for a plenitude of subgame-perfect equilibria (SPE). Here, we intend to minimize complexity by focusing on equilibria that satisfy the following assumption.

Assumption 1.

(i) At any time $t$, the entrepreneurs' expectations about future IPR enforcement $\Omega_{t+2}^{\prime}$ do not depend on $\omega_{j, t+1}$.

(ii) Each government $j$ takes $N_{t}, \omega_{n, t}, \omega_{s, t}\left(\omega_{k, t+1}, k \neq j\right)$, and item (i) as given and maximizes (8) subject to (6) according to its expectations $\Omega_{t+2}^{g}$. Governments do not condition their choices on the history of play before time $t$.

(iii) Given (i) and (ii), expectations are rational; i.e., $\Omega_{t+2}^{g}=\Omega_{t+2}^{\prime}=\Omega_{t+2}$.

Two remarks are in order. First, in item (ii), we have used parentheses for the other region's IPR enforcement choice at time $t$, because this is taken as given by each government in the game where IPR enforcement is chosen decentrally. Later we consider regimes where a government is able to determine both regions' enforcement levels, in which, of course, the other region's IPR enforcement is not taken as given. Second, given item (i) of Assumption 1, the entrepreneurs' expectations can only be rational if the future governments' optimal enforcement 
choices do not depend on the stock of technological knowledge. This is the case, as we will see later. As a consequence, the economy jumps into a steady state with constant growth of the technology stock $N$ in the initial period. ${ }^{28}$

\section{DECENTRALIZED ENFORCEMENT OF INTELLECTUAL PROPERTY RIGHTS}

In this section, we examine the strategic interaction between governments with respect to their national levels of IPR enforcement. We focus on SPE in the steady state satisfying Assumption 1. By "steady state," we refer to a situation where the technology stock $N$ (and consequently per capita output and consumption) grows at a constant rate and expectations about IPR enforcement are stationary, i.e., $\omega_{j, t+1}=\omega_{j, t}=\omega_{j}$ for all $j$ and $t$. In the next two subsections, we study the South's and the North's maximization problems and describe the unique SPE in the steady state thereafter.

\subsection{The Problem of the South}

The objective function of the government in the South at time $t$ can be written as

$$
W_{s, t}=\sum_{\tau=t}^{t+1} \beta^{\tau-t} N_{\tau} \lambda_{s}\left[Z+\omega_{s, \tau}(D-P)\right]
$$

where $Z \equiv \alpha^{\alpha /(1-\alpha)}-\alpha^{1 /(1-\alpha)}>0$ reflects the contribution of an intermediate to final output net of production costs for intermediates and $D \equiv \alpha^{2 \alpha /(1-\alpha)}-$ $\alpha^{\alpha /(1-\alpha)}+\alpha^{1 /(1-\alpha)}-\alpha^{2 /(1-\alpha)}<0$ represents the deadweight-loss factor net of production costs for intermediates. The expression $\omega_{s, \tau} N_{t} \lambda_{s} P$ indicates the profits accruing to the technology owners in the North. The South's objective (9) and the constraint (6) reveal the government's trade-off between static efficiency and dynamic gains: Stronger IPR enforcement involves higher deadweight losses and profit flows to the North, whereas it increases the incentives to innovate in the North (via $E_{t}$ ) and thereby leads to higher productivity of domestic final-good production in the South. When the South's optimization problem is solved, the reaction function along the balanced growth path with $\omega_{j, t+1}=\omega_{j, t}=\omega_{j}$ is $^{29}$

$$
\omega_{s}^{r}\left(\omega_{n}\right)=-\left(\frac{1-\beta}{2-\beta}\right)\left[\frac{Z}{D-P}+\frac{2 \Delta}{\beta P}\left(1+\frac{\lambda_{n}}{\lambda_{s}}\right)\right]-\frac{1}{2-\beta} \frac{\lambda_{n}}{\lambda_{s}} \omega_{n},
$$

where $\lambda \equiv \lambda_{n}+\lambda_{s}$ denotes the effective size of the world market and $\Delta \equiv \frac{\delta}{\lambda}$ represents the North's research capacity relative to the aggregate effective market size. This notation turns out to be very convenient for separating the effects of the aggregate world market size, $\lambda$, from those of the relative effective market sizes, $\frac{\lambda_{n}}{\lambda_{s}}$. In light of (10), we establish the following proposition: 
PROPOSITION 1 (IPR Enforcement in the South).

(i) The steady-state level of IPR enforcement in the South is a strategic substitute for IPR enforcement in the North.

(ii) For given $\omega_{n}$, the South's IPR enforcement increases with the effective market size of the South, $\lambda_{s}$, and with the research productivity of the North-i.e., it is decreasing in $\Delta$.

Item (i) originates from the fact that IPR enforcement constitutes a global public good as far as R\&D incentives are concerned. With respect to item (ii), the South's impact on the value of a patent becomes larger when it exhibits a larger effective market size, thereby reducing its incentive to free ride on the North's protection levels. ${ }^{30}$

\subsection{The Problem of the North}

In contrast to the government's objective in the South, the government in the North additionally accounts for R\&D expenditures, $E_{t}^{2} / 4 \delta$, and profit flows from the South to the North, $\omega_{s, t} N_{t} \lambda_{s} P$, which are subject to IPR enforcement in the South. Hence, the North's government maximizes

$$
W_{n, t}=\sum_{\tau=t}^{t+1} \beta^{\tau-t} N_{\tau}\left[\lambda_{n}\left(Z+\omega_{n, \tau} D\right)+\lambda_{s} \omega_{s, \tau} P-\frac{E_{\tau}^{2}}{4 \delta}\right],
$$

subject to (6). We obtain the first-order condition

$$
\begin{aligned}
- & N_{t} \frac{E_{t}}{2 \delta} \lambda_{n} P+N_{t+1} \lambda_{n} D+N_{t} \frac{\beta \lambda_{n} P}{2 \delta} \\
& \times\left[\lambda_{n}\left(Z+\omega_{n, t+1} D\right)+\lambda_{s} \omega_{s, t+1} P-\frac{E_{t+1}^{2}}{4 \delta}\right]=0 .
\end{aligned}
$$

A marginal increase in $\omega_{n, t+1}$ involves higher $\mathrm{R} \& \mathrm{D}$ costs in period $t$ lowering current consumption. This is reflected by the first term in (12). The second term represents the marginal increase in the deadweight loss in period $t+1 .{ }^{31}$ Finally, the marginal benefits are captured by the last summand of (12), which multiplies the additional number of innovations induced by the marginal increase in IPR enforcement, $N_{t+1}-N_{t}=N_{t} \frac{\beta \lambda_{n} P}{2 \delta}$, by the future welfare gains per innovation as expressed by the term in brackets.

From (12), we obtain in the steady state

$$
R_{n}\left(\omega_{n}, \omega_{s}\right) \equiv \frac{\tilde{E}}{2 \Delta}(D-P)+D+\frac{\beta P}{2 \Delta}\left[\frac{\lambda_{n}}{\lambda}\left(Z+\omega_{n} D\right)+\frac{\lambda_{s}}{\lambda} P \omega_{s}-\frac{\tilde{E}^{2}}{4 \Delta}\right]=0,
$$

where $\tilde{E}=E / \lambda$. Note that $\tilde{E}$ depends only on the relative effective market sizes, $\lambda_{n} / \lambda_{s}$, and not on $\lambda$. Equation (13) implicitly defines the reaction function of 
the North, $\omega_{n}^{r}\left(\omega_{s}\right)$. In the first term of (13), we combined the R\&D costs and the deadweight losses of the innovations created in period $t$, whereas the second term represents the deadweight losses resulting from enforcing the patents created before time $t$. The government's future welfare gains induced by a marginal increase in the North's level of IPR enforcement are still captured in the third term. In the Appendix, we show

LEMMA 1.

(i) There exists a unique economically sensible solution $\omega_{n}^{r}\left(\omega_{s}\right)$ to $R_{n}\left(\omega_{n}, \omega_{s}\right)=$ 0.

(ii) The North's reaction function $\omega_{n}^{r}\left(\omega_{s}\right)$ is strictly decreasing and strictly concave on the relevant interval $[0,1]$.

Lemma 1's implication of strategic substitutability between $\omega_{n}$ and $\omega_{s}$ from the perspective of the North is not obvious. A higher $\omega_{s}$ implies higher profit inflows from the South to the North for all active patents and for those intermediates that are developed in $t$. On one hand, this increases the North's incentives to tighten its level of IPR enforcement. On the other hand, the global public good problem with respect to R\&D incentives acts to reduce IPR enforcement in the North when the South increases its enforcement level. As verified in the proof of Lemma 1, the public good aspect dominates. Hence, national levels of IPR enforcement are strategic substitutes for foreign enforcement levels.

\subsection{Equilibrium}

The reaction functions of the North, $\omega_{n}^{r}\left(\omega_{s}\right)$, and the South, $\omega_{s}^{r}\left(\omega_{n}\right)$, possess only one potentially economically meaningful intersection, which we denote by $\left(\omega_{n}^{x}, \omega_{s}^{x}\right){ }^{32}$ However, the intersection may lie outside of the feasible set $[0,1]^{2}$. To account for corner solutions, let us introduce the notation $\hat{z} \equiv \max \{\min \{z, 1\}, 0\}$ and $\hat{z}(x) \equiv \max \{\min \{z(x), 1\}, 0\}$ for a constant $z$ and a function $z(x)$, respectively. Now we are able to characterize the levels of IPR enforcement in a steady-state $\operatorname{SPE},\left(\omega_{n}^{e}, \omega_{s}^{e}\right)$.

PROPOSITION 2 (Steady-State SPE). In the steady state, there exists a unique SPE of the IPR enforcement game satisfying Assumption 1. The unique enforcement levels at equilibrium are characterized by

$$
\begin{aligned}
& \omega_{n}^{e}= \begin{cases}\hat{\omega}_{n}^{r}(0), & \text { if } \omega_{s}^{x} \leq 0, \\
\hat{\omega}_{n}^{x}, & \text { if } \omega_{s}^{x} \in(0,1), \\
\hat{\omega}_{n}^{r}(1), & \text { if } \omega_{s}^{x} \geq 1,\end{cases} \\
& \omega_{s}^{e}= \begin{cases}\hat{\omega}_{s}^{r}(0), & \text { if } \omega_{n}^{x} \leq 0, \\
\hat{\omega}_{s}^{x}, & \text { if } \omega_{n}^{x} \in(0,1), \\
\hat{\omega}_{s}^{r}(1), & \text { if } \omega_{n}^{x} \geq 1 .\end{cases}
\end{aligned}
$$

In the proof in Appendix A.2, we show that there is only one unique economically sensible intersection of the reaction functions of the North and the 

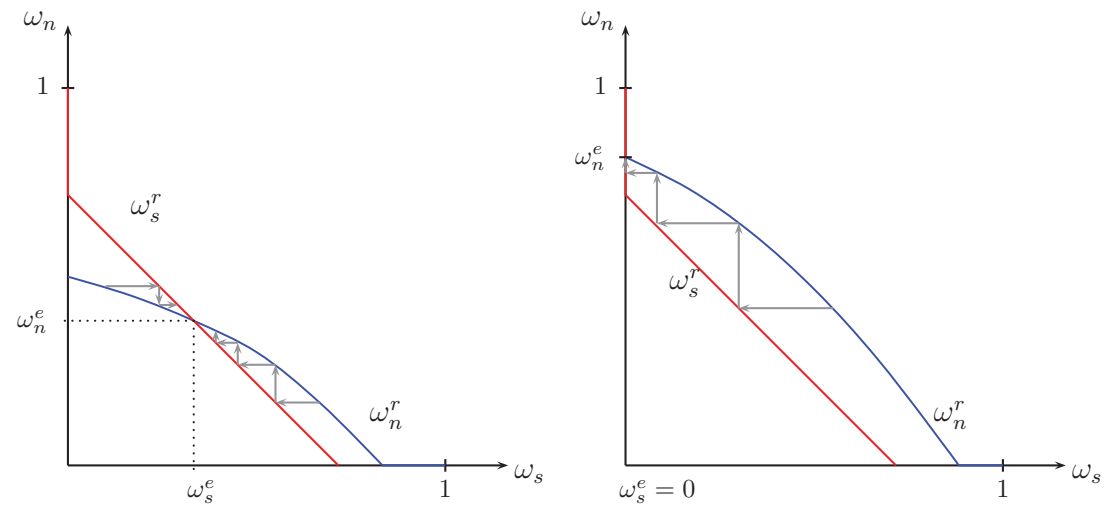

FIGURE 1. Equilibrium in the decentralized IPR enforcement game.

South. Depending on the parameter values, this intersection will be in the interior of the feasible set of enforcement levels $[0,1]^{2}$, or at one of the boundaries. Figure 1a illustrates the case of an interior equilibrium, whereas Figure $1 \mathrm{~b}$ depicts an equilibrium at the boundary of the feasible set. Proposition 2 characterizes the different cases. As can be observed in the graphs and as shown in the proof, for all $\omega_{s}>\omega_{s}^{e}$, the reaction function of the North, $\omega_{n}^{r}$, lies above that of the South, $\omega_{s}^{r}$, and vice versa for $\omega_{s}<\omega_{s}^{e}$. This implies that the equilibrium is unique and stable, in the sense that a simple process of steady-state best responses converges to the unique steady-state equilibrium. The arrows in Figure 1 indicate such adjustment dynamics.

Note that in the case of zero IPR enforcement in the South, i.e., $\omega_{s}^{e}=0$, both countries' equilibrium enforcement levels are identical to the ones they would implement in a closed economy. Given $\omega_{s}^{e}>0$, trade opening between North and South lowers the enforcement level in the North and enhances the level of enforcement in the South compared to autarky. The reason for the former is that the regions' IPR enforcement levels are strategic substitutes, whereas the latter originates from the South's internalizing the effect of its IPR enforcement level on R\&D incentives in the North.

\subsection{The Roles of Research Capacity and Market Sizes}

In our model, the enforcement levels in the steady-state SPE are entirely determined by the "primitives" $\alpha, \beta, \Delta$, and $\lambda_{n} / \lambda_{s}$. Our interest centers on how the decentralized steady-state equilibrium is affected (1) by the research capacity of the North and the global effective market size captured by the parameter $\Delta$ and (2) by the relative effective market sizes of the North and the South, $\frac{\lambda_{n}}{\lambda_{s}}$, for a given aggregate market size, i.e., for a given $\Delta .{ }^{33}$ 
We begin with $\Delta$. Perceiving $\omega_{n}^{e}$ and $\omega_{s}^{e}$ as functions of $\Delta$, we obtain

LEMMA 2. In an interior equilibrium where $\left(\omega_{n}^{e}, \omega_{s}^{e}\right) \in(0,1)^{2}$,

(i) $\omega_{n}^{e}$ is strictly concave in $\Delta$.

(ii) $\omega_{s}^{e}$ is strictly convex in $\Delta$.

In the proof given in the Appendix, we first show that $\omega_{n}^{e}$ is strictly concave in $\Delta$ in an interior equilibrium. As far as IPR enforcement levels in the South are concerned, $\omega_{s}^{e}$ is a declining line in $\Delta$ if there is no IPR enforcement in the North. For positive protection levels in the North, the South's enforcement level must be strictly below this line, as the protection level of the North acts as a strategic substitute. Consequently, the protection level of the South becomes convex, because IPR enforcement in the North is concave.

To fully characterize the comparative statics, we have to account for corner solutions. There exists a critical level $\Delta_{j}^{0}$, for both regions individually, such that for any $\Delta>\Delta_{j}^{0}$, country $j$ is not willing to enforce IPRs. ${ }^{34}$ This implies for the situation where $\Delta_{s}^{0}<\Delta_{n}^{0}$-i.e., the South's critical threshold level is smaller than that of the North-that for all $\Delta_{n}^{0}>\Delta>\Delta_{s}^{0}$, the South does not offer protection at equilibrium, whereas the North acts as in autarky. The opposite holds true in the situation where $\Delta_{n}^{0}<\Delta_{s}^{0}$. In the following (see Proposition 3), we focus on the case $\Delta_{s}^{0}<\Delta_{n}^{0}$ and define $\Delta^{0} \equiv \Delta_{s}^{0}$ as the smallest threshold corresponding to the South. This condition seems to match reality more closely than the opposite case, as it implies a minimum effective market size of the North relative to the South,

$$
\frac{\lambda_{n}}{\lambda_{s}}>\frac{D}{D-P} .
$$

Note that the right-hand side of (14) is smaller than one. Hence the inequality is always satisfied if $\lambda_{n}>\lambda_{s}$, but it also holds if $\lambda_{n}$ is not too much smaller than $\lambda_{s}$. In the next proposition, we characterize the comparative statics of equilibrium IPR enforcement levels with respect to changes in $\Delta$ given that condition (14) holds.

PROPOSITION 3 (Effect of $\Delta$ on IPR Enforcement). If $\lambda_{n} / \lambda_{s}>\frac{D}{D-P}$, then

(i) $\omega_{s}^{e}$ is positive and strictly decreasing with $\Delta$ for all $\Delta<\Delta^{0}$, and $\omega_{s}^{e}=0$ for all $\Delta \geq \Delta^{0}$.

(ii) For interior values, $\omega_{n}^{e}$ exhibits an inverted $U$-shaped relationship with $\Delta$. $\omega_{n}^{e}$ is identical to its value in autarky for $\Delta>\Delta^{0}$.

(iii) There exists a unique value $\Delta^{x}<\Delta^{0}$ where $\omega_{n}^{e}=\omega_{s}^{e}$. For all interior equilibria, $\omega_{n}^{e}<\omega_{s}^{e}$ if $\Delta<\Delta^{x}$, and $\omega_{n}^{e}>\omega_{s}^{e}>0$ if $\Delta>\Delta^{x}$.

The proof can be found in the Appendix. The content of Proposition 3 is illustrated in Figure 3. To gain an intuition, we depict in Figure 2 the changes of the regions' reaction functions in response to a larger effective research capacity in the North, that is, in response to a decline in $\Delta$. As can be observed, the South's reaction function moves to the right when $\Delta$ becomes smaller, because a smaller 


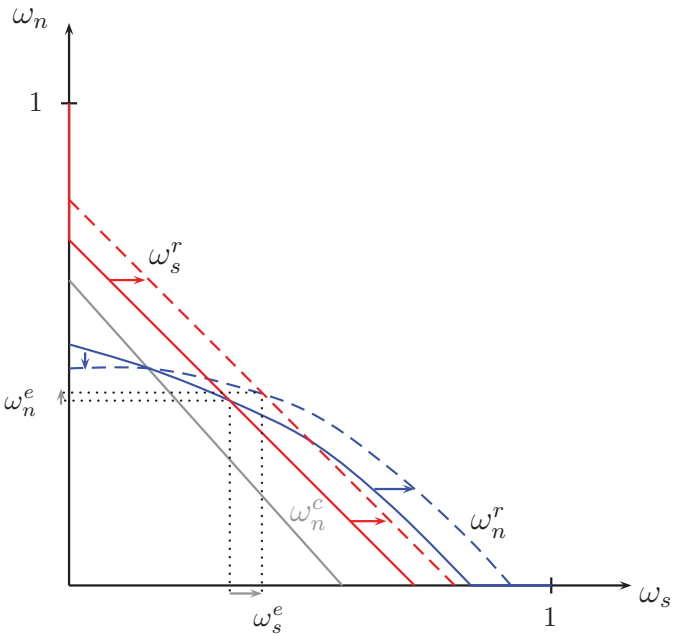

FIGURE 2. Responses of reaction functions to a decrease in $\Delta$.

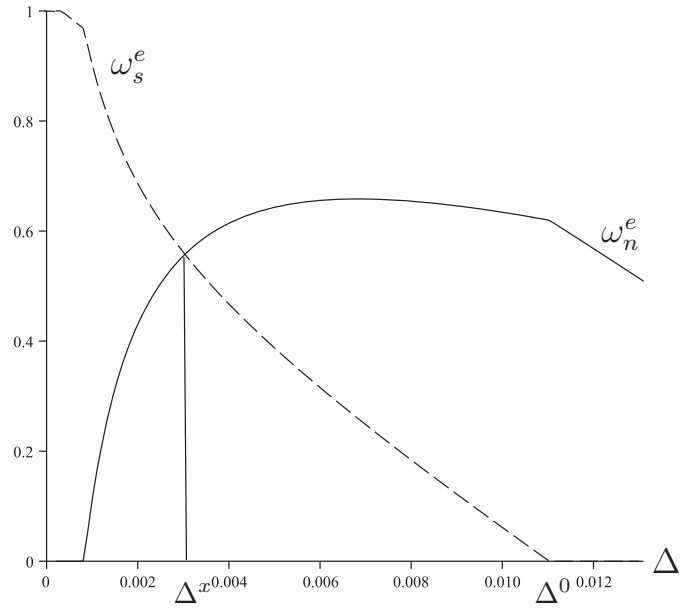

FIGURE 3. Steady-state equilibrium pairs $\left(\omega_{n}^{e}, \omega_{s}^{e}\right)$ dependent on $\Delta$, with $\alpha=0.3 ; \beta=$ $0.3 ; \lambda=1 ; \lambda_{n}=0.445$.

value of $\Delta=\frac{\delta}{\lambda}$ implies a larger lever exercised by the South's IPR enforcement on innovation incentives in the North. The convex shape for interior equilibrium values of IPR enforcement in the South, $\omega_{s}^{e}$, as illustrated in Figure 3, arises from the public-good aspect of IPR enforcement on R\&D incentives as discussed earlier.

In contrast to the literature, our model predicts an inverted U-shaped relation between the North's level of IPR enforcement and $\Delta$. An intuition for this result can be gained from scrutiny of the North's reaction function (13). Using the 
implicit-function theorem, the partial derivative of $\omega_{n}^{r}\left(\omega_{s}\right)$ with respect to $\Delta$ can be written as $\frac{\partial \omega_{n}^{r}}{\partial \Delta}=-\frac{\partial R_{n}\left(\omega_{n}, \omega_{s}\right)}{\partial \Delta} / \frac{\partial R_{n}\left(\omega_{n}, \omega_{s}\right)}{\partial \omega_{n}}$. As we show in the Appendix, the denominator is negative, implying that the sign of $\partial \omega_{n}^{r} / \partial \Delta$ is identical to that of $\partial R_{n}\left(\omega_{n}, \omega_{s}\right) / \partial \Delta$, which may be positive or negative. On one hand, a decline in $\Delta$ involves an increase in the number of innovations, $(\beta P / 2 \Delta)$. On the other hand, it increases current $\mathrm{R} \& \mathrm{D}$ expenditures and future deadweight losses [first term in (13)]. Additionally, welfare per innovation [term in brackets in (13)] declines when $\Delta$ becomes smaller because next period's $R \& D$ expenditures increase, as well.

As we can also observe in (13), both the marginal benefits and the marginal costs of an increase in IPR enforcement in the North depend on the actual strength of IPR enforcement. Therefore, we can identify a critical level of IPR enforcement $\omega_{n}^{c}\left(\omega_{s}\right)$ where the marginal benefits increase more than the marginal costs in response to a decrease in $\Delta$ if $\omega_{n}^{r}\left(\omega_{s}\right)<\omega_{n}^{c}\left(\omega_{s}\right)$ and vice versa for $\omega_{n}^{r}\left(\omega_{s}\right)>\omega_{n}^{c}\left(\omega_{s}\right) .{ }^{35}$ The consequent change in the North's reaction function $\omega_{n}^{r}$ is illustrated in Figure 2. Hence the new equilibrium after a decrease of $\Delta$ is at the intersection of the dashed reaction functions in Figure 2. From the graph we cannot infer a general pattern of how the equilibrium IPR enforcement levels will react to a change in $\Delta$. However, we show in the Appendix that when $\Delta$ is large, the benefits of a increase in $\omega_{n}$ in response to a marginal decrease in $\Delta$ (the larger number of innovations) increase more than the marginal costs (additional R\&D costs and deadweight losses). The opposite is the case when $\Delta$ is small. This implies an inverted U-shaped relation between $\omega_{n}^{e}$ and $\Delta$, as depicted in Figure 3 .

It is important to emphasize that this result is not an implication of convex R\&D costs at the research lab level. The central assumptions behind this result are that the government does not take full account of the future benefits of R\&D and that it enforces all active patents at the same strength. It is straightforward to show that in the case of a far-sighted government that could commit to a particular enforcement level for each vintage over the entire lifetime of its patent [as in Grossman and Lai (2004)], a monotonically declining relationship between $\omega_{n}$ and $\Delta$ would result $^{36}$ — similarly in a one-shot game where the government determines the level of IPR enforcement once and for all. The governments' limited time horizons and the necessity to enforce all active patents at the same strength result in different weights between the marginal benefits and the marginal costs of IPR enforcement in the government's first-order condition. Although the government can only influence the profit flows and deadweight losses in the next period, the induced additional costs for $R \& D$ that accrue in the current period account for the entire net present value of future profits. The latter cost term takes the dominant role for small values of $\Delta$, leading to an increasing relationship between IPR enforcement and $\Delta$ in the North. In contrast, the South's decision problem is independent from R\&D expenditures, so that the dynamic gains from the perspective of the South are monotonically increasing with the research productivity of the North. As a consequence of this result, we may find lower IPR enforcement levels in the North than in the South for sufficiently small $\Delta$, and vice versa if $\Delta$ is sufficiently large. 
Before turning our attention to the comparative statics with respect to relative market sizes, $\lambda_{n} / \lambda_{s}$, we verify that in interior equilibria, the global rate of growth on the balanced growth path increases when the research capacity becomes larger, even though the North's level of IPR enforcement may be declining at low values of $\Delta$.

PROPOSITION 4 (Effect of $\Delta$ on Steady-State Growth). In interior equilibria $\left(\omega_{n}^{e}, \omega_{s}^{e}\right) \in(0,1)^{2}$, the global steady-state growth rate strictly decreases with $\Delta$.

The proof can be found in Appendix A.5. Finally we turn to the role of relative market sizes for IPR enforcement and economic growth. We focus again on interior equilibria.

PROPOSITION 5 (Effect of Relative Effective Market Size). In interior equilibria $\left(\omega_{n}^{e}, \omega_{s}^{e}\right) \in(0,1)^{2}$, both countries' IPR enforcement levels increase with their relative effective market sizes. The steady-state growth rate is unaffected by the relative effective market sizes.

The proof is provided in Appendix A.6. Governments tighten IPR enforcement in response to an increase in their relative market share, because their relative levers for inducing innovations increase. It is possible to draw a graph similar to Figure 2 in order to illustrate the shifts in the regions' reaction functions in response to a change in relative effective market size. We observe directly in the South's reaction function (10) that the South's IPR enforcement level will increase when the South becomes relatively larger. This involves a shift to the upper right of the reaction function in a coordinate plane like the one in Figure 2. The statement regarding the North in Proposition 5 cannot be derived directly from its reaction function (13), as there are conflicting forces, depending again on the actual levels of IPR enforcement: Whereas a relatively larger effective market size of the South reduces the marginal welfare benefits of additional innovations induced by a marginal increase in IPR enforcement, it increases the profit flows from the South. Similarly, the change of the expected value of a patent depends on the actual levels of IPR enforcement in the different regions, as the profit flows in the North decline while those coming in from the South increase. Hence, we again find critical values $\omega_{n}^{c}\left(\omega_{s}\right)$ separating the part of the North's reaction function that increases from the part that decreases in response to a change in relative effective market size. However, as we show analytically in the Appendix, in contrast to a change in $\Delta$, the regions' equilibrium enforcement levels will both increase in their relative effective market sizes. In fact, the region becoming relatively smaller by a marginal change in the relative effective market sizes reduces its IPR enforcement level in a symmetric way so that the global discounted profits to be earned in expectation by an entrepreneur in the North remain unchanged. As a consequence, the steady-state growth rate remains unaffected. In sum, a change in a country's effective market size will affect the growth 
rate only through its effect on the total world market size but not via a change in its relative market size.

\section{HARMONIZATION OF INTELLECTUAL PROPERTY RIGHTS ENFORCEMENT}

As discussed in the Introduction, some countries make an effort to harmonize IPR enforcement globally, e.g., via ACTA. In this respect, it is interesting to explore which harmonized IPR enforcement level the governments of regions $n$ and $s$ would like to implement given that they had the power to do so. These enforcement levels may shed light on the differences that need to be bridged in international negotiation rounds. ${ }^{37}$

In our context, harmonization means that both regions are subject to the same level of IPR enforcement. Hence, expected discounted profits per invention are specified as

$$
E_{t}^{h}=\sum_{\tau=t+1}^{\infty} \beta^{\tau-t} \omega_{j, \tau}^{h} P \lambda,
$$

where $\omega_{j, \tau}^{h}$ represents the harmonized IPR enforcement level preferred by region $j .{ }^{38}$ The evolution of the technology stock is again captured by (6), where discounted profits are now determined by (15), so that

$$
N_{n, t+1}=N_{t}\left(1+\frac{E_{t}^{h}}{2 \delta}\right) .
$$

With respect to the governments' decision problems, we stay with the two major assumptions that there is only commitment on IPR enforcement for one period and that all active patents have to be enforced at the same strength. One may argue that an agreement in the international arena could serve as a commitment device, partially at least. However, particularly where IPR enforcement is concerned rather than formal laws, there is also the possibility of renegotiations after each period. Here, we stress the latter point. ${ }^{39}$ This also allows us to directly compare the results with the ones in the decentralized setting.

\subsection{Desired Harmonized Enforcement Level of the South}

We begin with the optimization problem of the government located in the South, which chooses a single level of IPR enforcement that applies to both regions. The South maximizes

$$
W_{s, t}^{h}=\sum_{\tau=t}^{t+1} \beta^{\tau-t} N_{\tau} \lambda_{s}\left[Z+\omega_{s, \tau}^{h}(D-P)\right],
$$


subject to (16). Along the balanced growth path, we obtain as the preferred harmonized enforcement level of the South ${ }^{40}$

$$
\omega_{s}^{h}=-\frac{1-\beta}{2-\beta}\left(\frac{Z}{D-P}+\frac{2 \Delta}{\beta P}\right) .
$$

Compared with the decentralized protection game [see equation (10)], the desired harmonized enforcement level of the South is higher, because the marginal benefits in terms of R\&D incentives increase as a result of the larger market size in the optimization problem ( $\lambda$ versus $\lambda_{s}$ ) for which enforcement is determined. At the same time, the marginal costs in terms of deadweight losses in the South and profit outflows to the North remain as in the decentralized setting. In addition, $\omega_{s}^{h}$ is independent of relative market sizes. Equation (18) reveals that $\omega_{s}^{h}$ increases with the North's research capacity but is independent of the relative effective market sizes. We summarize these observations in the next proposition.

PROPOSITION 6 (Desired Harmonized IPR Enforcement of the South). The preferred harmonized level of IPR enforcement of the South increases with the North's research productivity and the global effective market size, but is independent of the relative market sizes.

\subsection{Desired Harmonized Enforcement Level of the North}

The objective of the government in the North includes profit inflows from the South, which are-in contrast to the decentralized IPR enforcement game-subject to the harmonized enforcement level of the North,

$$
W_{n, t}^{h}=\sum_{\tau=t}^{t+1} \beta^{\tau-t} N_{\tau}\left[\lambda_{n}\left(Z+\omega_{n, \tau}^{h} D\right)+\lambda_{s} P \omega_{n, \tau}^{h}-\frac{\left(E_{\tau}^{h}\right)^{2}}{4 \delta}\right] .
$$

In the steady state, the North's optimal level of global IPR enforcement, $\omega_{n}^{h}$, satisfies $^{41}$

$$
\begin{aligned}
R_{n}^{h}\left(\omega_{n}^{h}\right) & \equiv \frac{\tilde{E}^{h}}{2}(D-P)+\Delta\left(D+\frac{\lambda_{s}}{\lambda_{n}} P\right) \\
+\frac{\beta P}{2} & {\left[Z+\omega_{n}^{h}\left(D+P \frac{\lambda_{s}}{\lambda_{n}}\right)-\frac{\left(\tilde{E}^{h}\right)^{2}}{4 \Delta}\left(1+\frac{\lambda_{s}}{\lambda_{n}}\right)\right]=0, }
\end{aligned}
$$

where $\tilde{E}^{h}=\frac{\beta}{1-\beta} P \omega_{n}^{h}$. The next proposition verifies that (20) possesses a unique economically sensible solution and describes the effects of changes in $\Delta$ and the relative market sizes, $\lambda_{n} / \lambda_{s}$, on the preferred harmonized enforcement level of the North.

PROPOSITION 7 (Desired Harmonized IPR Enforcement of the North).

There exists a unique economically sensible solution to the North's optimization problem. The North's desired harmonized level of global IPR enforcement 
depends on its research productivity and its relative effective market size as follows:

(i) If $\frac{\lambda_{n}}{\lambda_{s}}<-\frac{P}{D}$, then the North's desired level of global IPR enforcement, $\omega_{n}^{h}$, increases with $\Delta$.

(ii) If $\frac{\lambda_{n}}{\lambda_{s}}>-\frac{P}{D}$, then there exists a unique value $\Delta^{m}>0$ where for all $\Delta>(<)$ $\Delta^{m}$, the North's desired level of IPR enforcement, $\omega_{n}^{h}$, decreases (increases) with $\Delta$.

(iii) There exists a unique value $\bar{\Delta}>0$, where for all $\Delta>(<) \bar{\Delta}$, the North's desired level of IPR enforcement, $\omega_{n}^{h}$, decreases (increases) with $\frac{\lambda_{n}}{\lambda_{s}}$.

The proof can be found in Appendix A.7. Concerning the effects of research capacity and global effective market size $(\Delta)$, Proposition 7 distinguishes two cases. In the first, (i), an increase of global IPR enforcement involves less additional deadweight losses in the North $\left(-\lambda_{n} D\right)$ than additional profit inflows from the South $\left(\lambda_{s} P\right)$. Thus, the only costs associated with IPR enforcement are the research costs, and the North's main objective in enforcing global IPRs is to reap profits from the South. The latter is cheaper when $\Delta$ increases, as this implies lower aggregate $\mathrm{R} \& \mathrm{D}$ expenditures. As a consequence, there is a positive relation between $\omega_{n}^{h}$ and $\Delta$. In the second case, (ii), the profit inflows from the South are lower than the deadweight losses in the North incurred by an increase in global IPR enforcement. In this scenario, the North's first-order condition with respect to its most preferred harmonized enforcement level shows a structure similar to that in the decentralized game, with the difference that part of the North's deadweight losses are compensated for by higher profit inflows from the South. As a consequence, we also obtain an inverted U-shaped relationship between $\omega_{n}^{h}$ and $\Delta$ for which the same intuition as provided in the discussion of the decentralized setting can be applied.

In contrast to the decentralized enforcement game, the relative effective market size exhibits a nonmonotonic effect on the North's desired level of IPR enforcement, as indicated by item (iii) of Proposition 7. The reason is that changes in the relative effective market sizes change the weights attached to the different components in the North's objective function. As an illustration, consider the effect of an increase of $\lambda_{n} / \lambda_{s}$ given $\lambda$ on the government's welfare objective in period $t$. The latter is written as

$$
N_{t}\left[\lambda_{n} Z+\omega_{n, t}^{h}\left(\lambda_{n} D+\lambda_{s} P\right)-\frac{\left(E_{t}^{h}\right)^{2}}{4 \Delta}\right] .
$$

Substituting $\lambda-\lambda_{n}$ for $\lambda_{s}$ and taking the derivative with respect to $\lambda_{n}$ given $\lambda$ yields

$$
N_{t}\left[Z+\omega_{n, t}^{h}(D-P)\right] .
$$

Apparently, the marginal change of the North's periodic welfare with respect to changes in its own relative market size (22) is structurally equivalent to the 
periodic welfare of the South (per effective market size) and is independent of research expenditures, because $E_{t}^{h}$ depends only on the effective world market size $\lambda$, which remains unchanged. Intuitively, a larger effective market size of the North gives higher weight to final-good production and deadweight losses in the North and lower weight to the profit inflow from the South. That is, an increase in the effective market size of the North gives higher weight to those components of the North's periodic welfare that are also present in the South's. Hence, the desired IPR enforcement level of the Northern government approaches that of the South when $\lambda_{n} / \lambda_{s}$ increases. However, it will never coincide with $\omega_{s}^{h}$, because $\omega_{n}^{h}$ represents the solution under autarky for $\lambda_{s}=0$ with R\&D expenditures still being positive. A graphical illustration is presented in Figure 4, where the solid gray line reflects the desired harmonized enforcement level of the North for a lower relative market size $\lambda_{n} / \lambda_{s}$ compared to the dark solid line. The dark solid curve is closer to the dashed line that represents the desired harmonized enforcement level of the South. ${ }^{42}$ According to this intuition and Proposition 7 (iii), we infer

PROPOSITION 8 (North's and South's Desired Harmonized IPR Enforcement). For interior values of $\omega_{n}^{h}$ and $\omega_{s}^{h}, \omega_{n}^{h}<\omega_{s}^{h}$ if $\Delta<\bar{\Delta}$, and $\omega_{n}^{h}>\omega_{s}^{h}$ if $\Delta>\bar{\Delta}$.

The proposition is illustrated in Figure 4, and a proof is provided in the Appendix. ${ }^{43}$ Proposition 8 implies that when the research productivity in the North is very high ( $\Delta$ sufficiently small), the South may even desire a higher harmonized enforcement level than the North. Because we typically observe stronger IPR enforcement in the developed Northern countries than in the developing Southern countries, we think that reality is described by $\Delta>\bar{\Delta}$ and $\Delta>\Delta^{x}$, implying that $\omega_{n}^{h}>\omega_{s}^{h}$ and $\omega_{n}^{e}>\omega_{s}^{e}$. Thus the North's desired harmonized enforcement level increases with the relative market size of the South, whereas its equilibrium enforcement level in the decentralized game declines. ${ }^{44}$ Consequently, a relatively larger Southern market widens the gap between $\omega_{n}^{h}$ and $\omega_{n}^{e}$. The opposite is true for the South: Its desired harmonized level is independent of the relative market sizes, whereas the equilibrium level $\omega_{s}^{e}$ increases with the South's relative market size. This implies that the difference between $\omega_{s}^{e}$ and $\omega_{s}^{h}$ becomes smaller, because $\omega_{s}^{e}<\omega_{s}^{h}$, as argued in Section 5.1.

In particular, with regard to the ACTA negotiations, our results suggest that small countries located in the North strongly favor tighter IPR enforcement, as they benefit most from higher profit inflows from the South, with the latter incurring correspondingly large amounts of deadweight losses.

\section{CONSTRAINED EFFICIENCY AND COMPARISON OF REGIMES}

What would be the maximum welfare that governments could achieve by coordinating their respective levels of IPR enforcement, but given their inability to escape their political-economy constraints? We have in mind a global government 


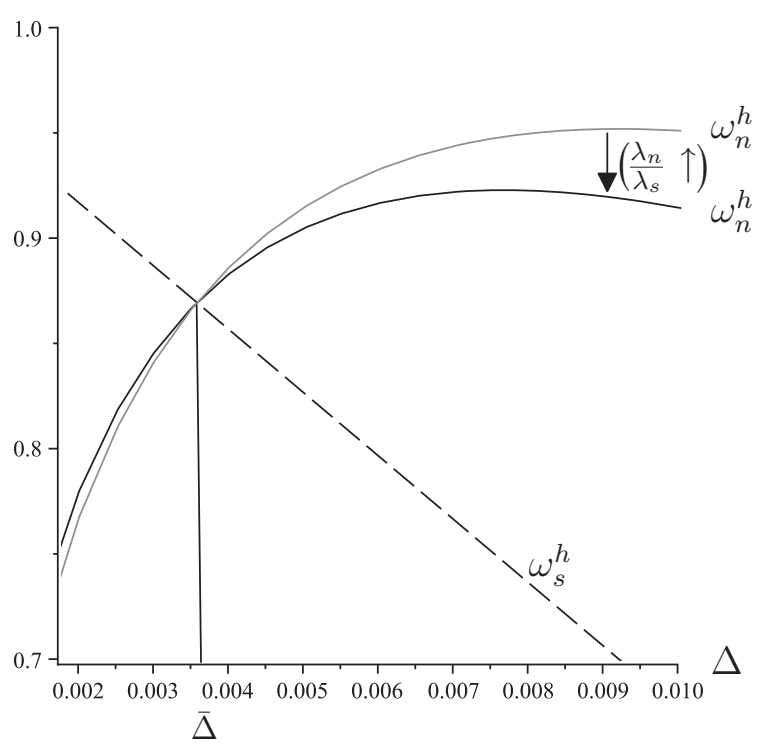

FIGURE 4. Desired harmonized IPR enforcement of the North (solid lines) in response to an increase in $\lambda_{n} / \lambda_{s}$ (gray versus black solid line). Dashed line: desired harmonized IPR enforcement level of the South. Parameters: $\alpha=0.3 ; \beta=0.35 ; \lambda=1 ; \lambda_{n}=0.78$.

choosing pairs of $\left(\omega_{n, t+1}, \omega_{s, t+1}\right)$ to maximize the sum of the regional governments' welfare. Because expected profits depend only on the path of $\Phi_{t}=$ $\lambda_{n} \omega_{n, t}+\lambda_{s} \omega_{s, t}$ and not on particular values of $\omega_{n, t}$ and $\omega_{s, t}$, we can rewrite the maximization problem of a global government in terms of $\Phi_{t} \cdot{ }^{45}$ Hence the constrained efficient pairs of IPR enforcement, $\left(\omega_{n, t+1}, \omega_{s, t+1}\right)$, are obtained by solving

$$
\max _{\Omega_{t+1}^{p}} W=\sum_{\tau=t}^{t+1} \beta^{\tau-t} N_{t}[Z \lambda+D \underbrace{\left(\lambda_{n} \omega_{n, t}+\lambda_{s} \omega_{s, t}\right)}_{\Phi_{t}}-\frac{E_{t}^{2}}{4 \Delta}],
$$

subject to (6). The necessary condition for a constrained welfare maximum in the steady state is

$$
D+\frac{\tilde{E}}{2 \Delta}(D-P)+\frac{\beta P}{2 \Delta}\left(Z+D \Phi / \lambda-\frac{\tilde{E}^{2}}{4 \Delta}\right)=0 .
$$

Sidestepping the multiplicity of optimal solutions to the global government's problem, we focus on the (unique) constrained efficient harmonized solution, where the optimal enforcement level $\omega^{p}$ is implemented in both regions and solves (24). In this case, we obtain $\Phi=\lambda \omega^{p}$ and (24) coincides with the firstorder condition of a closed economy with effective market size $\lambda$. 


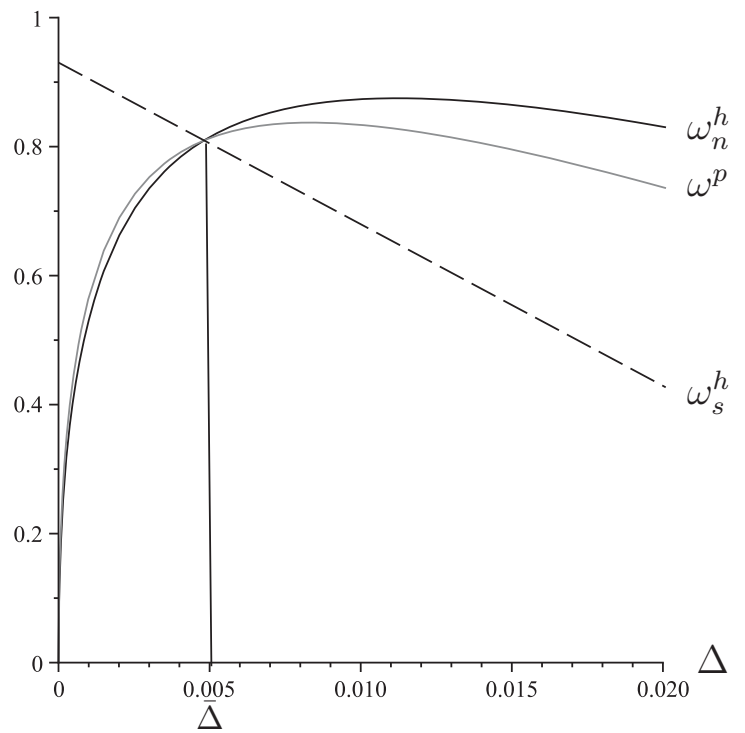

FIGURE 5. Comparison between the regimes: noncooperative enforcement, efficient solution, and preferred harmonized enforcement levels. Parameters: $\alpha=0.3 ; \beta=0.4 ; \lambda=$ $1 ; \lambda_{n}=0.78$.

The constrained efficient solution serves as a theoretical point of reference to which we relate the enforcement levels obtained from the preceding sections. The different levels of IPR enforcement are depicted in Figure 5. The regions' preferred harmonized enforcement levels and the constrained efficient enforcement levels intersect at $\bar{\Delta}$ so that $\omega_{n}^{h}>\omega^{p}>\omega_{s}^{h}$, if $\Delta>\bar{\Delta}$, whereas $\omega_{n}^{h}<\omega^{p}<\omega_{s}^{h}$, if $\Delta<\bar{\Delta}$.

The intuition behind this result can be described as follows: For $\lambda_{s} \rightarrow 0$ and $\lambda_{n} \rightarrow \lambda$ the preferred harmonized enforcement level of the North must equal the constrained efficient solution $\left(\omega_{n}^{h}=\omega^{p}\right)$, because the world economy consists of the North only. According to item (iii) of Proposition 7, $\omega_{n}^{h}$ increases with $\lambda_{s} / \lambda_{n}$ if $\Delta>\bar{\Delta}$, but declines if $\Delta<\bar{\Delta} \cdot{ }^{46}$ Hence, starting from the situation where $\lambda_{s}=0$ and $\lambda_{n}=\lambda$, an increase in $\lambda_{s} / \lambda_{n}$ turns $\omega_{n}^{h}$ counterclockwise around $\bar{\Delta}$, implying that $\omega_{n}^{h}>(<) \omega^{p}$ if $\Delta>(<) \bar{\Delta}$. As discussed in the preceding section, for a declining ratio $\lambda_{s} / \lambda_{n}, \omega_{n}^{h}$ approaches $\omega_{s}^{h}$ but will not coincide with it in the limit $\lambda_{s} / \lambda_{n} \rightarrow 0$. Accordingly, Proposition 8 implies that $\omega_{s}^{h}<(>) \omega^{p}$ for $\Delta>(<) \bar{\Delta}$. As a consequence, the constrained efficient IPR enforcement level is in between the desired harmonized enforcement levels of the North and the South for all $\Delta \neq \bar{\Delta}$.

Concerning the decentralized enforcement level in the North, we know from Proposition 5 that $\partial \omega_{n}^{e} / \partial\left(\lambda_{n} / \lambda_{s}\right)>0$. Moreover, in the situation where $\lambda_{n}=\lambda$, $\omega_{n}^{e}$ coincides with the constrained efficient enforcement level $\omega^{p} \cdot{ }^{47}$ An increase in $\lambda_{s} / \lambda_{n}$ thus implies that $\omega_{n}^{e}<\omega^{p}$. According to our previous discussion, it further 
involves $\omega_{n}^{e}<\omega_{n}^{h}$ for $\Delta \geq \bar{\Delta}$. However, this relation may not be satisfied for all $\Delta<\bar{\Delta} .{ }^{48}$ We summarize our observations in the following proposition.

PROPOSITION 9 (Comparison of IPR Enforcement Regimes).

(i) At $\Delta=\bar{\Delta}$ the regions' preferred harmonized enforcement levels correspond to the constrained efficient harmonized IPR enforcement; i.e., $\omega_{s}^{h}=\omega_{n}^{h}=$ $\omega^{p}$.

(ii) For $\Delta<\bar{\Delta}, \omega_{s}^{h}$ is above and $\omega_{n}^{h}$ below the constrained efficient level of IPR enforcement. For all $\Delta>\bar{\Delta}, \omega_{s}^{h}$ is below and $\omega_{n}^{h}$ above the constrained efficient level of IPR enforcement.

(iii) The decentralized equilibrium level of IPR enforcement in the North, $\omega_{n}^{e}$, is always below the constrained efficient level and lower than the North's desired harmonized enforcement level if $\Delta \geq \bar{\Delta}$.

The world economy is arguably best described by $\Delta>\bar{\Delta}$. As stated in Proposition 9 and depicted in Figure 5, the preferred harmonized enforcement level of the North exceeds the constrained efficient level, which in turn is higher than the preferred harmonized enforcement level of the South. Because the steady-state growth rate is a linear function of IPR enforcement, the implementation of $\omega_{n}^{h}$ would be most conducive for economic growth. ${ }^{49}$ On the other hand, for small values of $\Delta$, the decentralized game yields the lowest aggregate incentives for R\&D and consequently the lowest steady-state growth rate. Interestingly, the latter may even fall below the growth rate resulting if the South's desired harmonized level of IPR enforcement were adopted globally. ${ }^{50}$

\section{WELFARE}

Whether the South should adopt the IPR standards of the North is one of the most debated questions in the political arena. ${ }^{51}$ However, it is not clear to which IPR standards of the North the discussion refers: the equilibrium choice of the North or its desired harmonized enforcement level. Figure 5 in the preceding section suggests that even though the difference between the North's and the South's equilibrium choices can be substantial, the South's desired harmonized IPR enforcement level can be quite close to the North's equilibrium choice. Hence, a binding adoption of the North's equilibrium enforcement level might not be such a contentious issue, as opposed to the implementation of the North's most preferred harmonized protection level of IPRs. We therefore explore the welfare effects in the South resulting from the implementation of $\omega_{n}^{h}$ along the balanced growth path as compared to the implementation of $\omega_{s}^{h} .{ }^{52}$ Aggregate welfare in the South can be written as

$$
\bar{W}_{s}\left(\omega_{j}^{h}\right)=\frac{1}{1-\beta\left[1+g\left(\omega_{j}^{h}\right)\right]} \lambda_{s}\left[Z+\omega_{j}^{h}(D-P)\right],
$$

with $g\left(\omega_{j}^{h}\right)=\frac{P \omega_{j}^{h}}{2 \Delta} \frac{\beta}{1-\beta}$ and $j=n, s .{ }^{53}$ The results are depicted in Figure 6. 


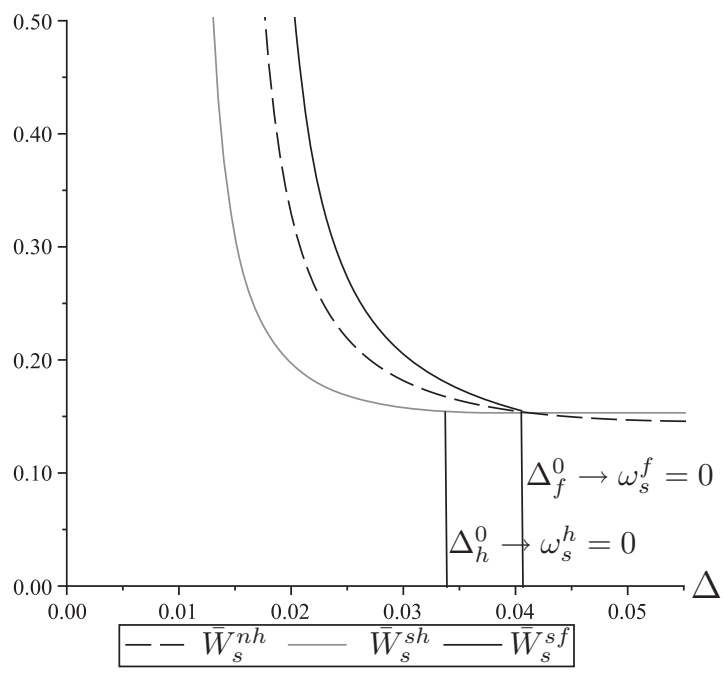

FIGURE 6. Welfare effects in the South due to the implementation of $\omega_{s}^{h}, \omega_{n}^{h}$, and $\omega_{s}^{f}$ as functions of $\Delta\left(\bar{W}_{s}^{s h}\right.$ corresponds to $\omega_{s}^{h} ; \bar{W}_{s}^{n h}$ corresponds to $\omega_{n}^{h} ; \bar{W}_{s}^{s f}$ corresponds to $\left.\omega_{s}^{f}\right)$.

The gray solid line reflects the South's overall welfare, $\bar{W}_{s}\left(\omega_{s}^{h}\right)$, obtained from its government's preferred harmonized enforcement level, whereas the dashed line represents the long-term welfare level, $\bar{W}_{s}\left(\omega_{n}^{h}\right)$, realized by accepting the Northern government's desired harmonized enforcement level. Figure 6 depicts the welfare levels for values of $\Delta$ higher than $\bar{\Delta}$ with $\omega_{n}^{h}>\omega_{s}^{h}$ according to Proposition 8 . The figure indicates that for a relatively high research capacity in the North, the implementation of $\omega_{n}^{h}$ would induce welfare gains in the South compared to the implementation of its own preferred harmonized enforcement level, $\omega_{s}^{h}$. For high values of $\Delta$, however, the South suffers welfare losses by implementing $\omega_{n}^{h}$ rather than $\omega_{s}^{h}$.

The result that the South gains in welfare from implementing the desired harmonized IPR enforcement level of the North can be explained by the Southern government's limited time horizon. To illustrate this, we calculate the simple one-shot solution to maximizing welfare in the South given by (25). That is, the government in the South selects the global level of IPR enforcement at $t=0$, which is then fixed for all time. The welfare level realized from the implementation of this enforcement level, which we denote by $\omega_{s}^{f}$, is indicated by the solid dark line in Figure $6{ }^{54}$ We use $\Delta_{f}^{0}$ to denote the value of $\Delta$ where for all $\Delta \geq \Delta_{f}^{0}$ even the full-commitment solution of the government in the South will imply no IPR enforcement. For a wide range of $\Delta$-values lower than $\Delta_{f}^{0}$, we directly observe in Figure 6 that the South's welfare level obtained from the implementation of the North's desired harmonized enforcement level approximates the one realized in the full-commitment case. The intuition is that the government in the South would enforce IPR more strongly if its planning horizon accounted for the entire future 
welfare associated with innovations. However, as we observe in the figure, at least for $\Delta \geq \Delta_{f}^{0}$, where the full-commitment solution involves no IPR enforcement, the implementation of a positive level of IPR enforcement $\omega_{n}^{h}$ entails welfare losses. Consequently, if the research capacity of the North is large, accepting the North's desired level of IPR enforcement in international negotiation rounds such as ACTA would foster long-term welfare in the South. However, the opposite is true when the research capacity is low. 55

\section{SUMMARY AND CONCLUSIONS}

Even though most countries have agreed to harmonize intellectual property rights by signing TRIPs, there is much dispute about the enforcement of IPRs in the world. This paper examines IPR enforcement in an endogenous growth framework with two open economies. We incorporate three assumptions that distinguish our paper from the previous literature and add realistic features to the model: In each economy all active patents are enforced at the same (endogenously chosen) strength, the governments cannot fully commit to IPR enforcement for the indefinite future and have limited planning horizons, e.g., because of reelection concerns.

Whereas the governments in the decentralized game provide too little IPR enforcement relative to the constrained efficient solution that maximizes the governments' aggregate welfare under the previous assumptions, both regions, the North and the South, desire higher IPR protection relative to the equilibrium enforcement levels if they were able to select a harmonized world enforcement level. Typically, the North's desired harmonized enforcement level is larger than the constrained efficient one, whereas that of the South is lower. The difference between the North's and the South's desired harmonized enforcement levels increases with the relative market size of the South, thus amplifying the clash of interests in international negotiations. Moreover, we find that the smaller a region's relative market size, the larger is the difference between its equilibrium choice and the ideal harmonized enforcement desired on the international level.

Concerning the discussion of whether the South suffers welfare losses from adopting the desired IPR enforcement levels of the North, our numerical welfare example suggests that as long as the North's research capacity is not too low, the South may well benefit in terms of overall long-term welfare. However, when the research capacity is low, the dynamic gains realized would not justify the large profit outflows even from a long-term welfare perspective.

It is frequently assumed in the political economy literature as well as in parts of the dynamic macroeconomic literature that governments act in a short-sighted way. Our paper highlights that such an assumption can imply counterintuitive results for very high levels of the North's research capabilities. In particular, the North's short-sighted government's IPR enforcement level in equilibrium and also the desired harmonized level may decline with its research productivity. As a 
consequence, the short-sighted government in the South may choose a higher equilibrium and desired harmonized enforcement level than the North.

With regard to ACTA, the countries working out the agreement correspond to what we have referred to as the innovative Northern countries in our analysis. Assuming that ACTA reflects their desired globally harmonized level of IPR enforcement, our results suggest that, under realistic research capabilities, the ACTA enforcement levels are higher than the globally efficient harmonized level of IPR enforcement and also higher than the desired harmonized enforcement levels in the South. This would increase the growth rates of both the North and the South. However, our numerical example suggests that the South will likely lose in terms of welfare. Consequently, even if the Northern countries will ratify the treaty, their hopes that ACTA will become a global pact by the less innovative Southern countries also signing the agreement will likely be disappointed.

Our paper opens up several avenues for future research. It would be interesting to extend the enforcement game to one where both regions are active in research and to consider more than two countries. Further, the framework developed can be used to study several important aspects of IPR protection such as blocking patents, differences in preferences between the countries, or principal-agent problems in $\mathrm{R} \& \mathrm{D}$ joint ventures and their consequences for long-run development.

\section{NOTES}

1. See EU Commission (2009). A similar picture is drawn in the annual Special 301 Reports by the U.S. Trade Representative; see Office of U.S. Trade Representative (2010). Recently, the OECD estimated the value of counterfeited products in foreign trade in 2007 as around \$270 billion [OECD (2009)].

2. Other authors hold that even though the TRIPs Agreement provides for mechanisms of law enforcement, these are not always implemented by the member countries [see, e.g., Cychosz (2003)].

3. In his recent book, Maskus (2012) also describes this new emphasis on IPR enforcement.

4. A comparison between ACTA and TRIPs can be found at, e.g., https://sites.google.com/ site/iipenforcement/.

5. The countries are Australia, Canada, the European Union, Japan, Mexico, Morocco, New Zealand, the Republic of Korea, Singapore, Switzerland, and the United States.

6. In 2006, the European Union adopted the IPR Enforcement Directive to harmonize IPR enforcement levels among its members and eschew civil procedures that are "unnecessarily complicated and costly or involve unreasonable time limits or unwarranted delays" [European Parliament (2004)].

7. See EU Commission (2012).

8. In principle, it would be possible that enforcement distinguished between a domestic product and an invention of a foreign country. In this paper, we do not address this case and focus on national treatment only.

9. For example, both politicians' monetary and nonmonetary rewards may depend on the welfare level during their term in office. According to a large literature on the political business cycle, the welfare during the term in office also affects the incumbent politicians' reelection probabilities [Oudiz and Sachs (1985); Drazen (2000); Persson and Tabellini (2000)]. There is also a literature on officemotivated politicians, so called populists, who pander to the public by pursuing short-term policies to maximize reelection chances. The concern of this literature is how to give incentives to implement 
projects that are beneficial in the long term but come at costs in the short term [see, e.g., Müller (2007); Gersbach (2004)].

10. The trade-off between static efficiency and dynamic gains was first discussed by Nordhaus (1969).

11. See Grossman and Lai (2004, p. 1642).

12. The major difference is that in Grossman and Lai (2004), the policy maker determines in each period of time the level of IPR protection only for the products invented in the same period but for the duration of their entire lifetime (i.e., until the products become obsolete). In our model, the policy maker decides in each period on the level of IPR enforcement of all products under de jure IPR protection but cannot commit to enforcement levels in future periods.

13. Helpman (1993) finds that stronger IPRs adversely affect the South's welfare and could be detrimental to the North as well, if only trade is considered.

14. Dinopoulos and Segerstrom (2007) study technology transfer driven by imitation and Dinopoulus and Segerstrom (2010) consider technology transfer within multinational firms via FDI. These papers confirm Lai (1998)'s results in a semiendogenous growth model.

15. More remotely related to our work are several interesting papers that expand this branch of the literature by including skill accumulation [Parello (2008)], analyzing catch-up dynamics of the South in product quality levels [Borota (2012)], and examining effects of patent policy on a country's income distribution in a closed economy [Kiedaisch (2009)].

16. Among these papers are Chin and Grossman (1990) and Deardorff (1992), who examine welfare effects in a North-South model with exogenous variations in IPRs, as well as Diwan and Rodrik (1991), who analyze IPRs endogenously chosen by the regional governments.

17. An overview of older empirical evidence, also on the (mostly positive) relation between IPR protection and economic growth, is provided in Maskus (2000).

18. Typically, studies such as Ginarte and Park (1997) trying to relate IPR protection to various characteristics of countries subsume under IPR enforcement statutory rather than de facto protection. IPR enforcement in Ginarte and Park (1997) includes whether (a) preliminary injunctions, (b) contributory infringement pleadings, and (c) burden-of-proof reversals are available. Ginarte and Park (1997) argue that there is no big gap between statuary and actual enforcement. However, the reports by the European Commission and the U.S. Trade Representative reveal a different picture. We are not aware of a good measure for de facto IPR enforcement that we could use to test our theory empirically.

19. We do not neglect that the South conducts R\&D; however, in a model where both regions innovate but Region $s$ possesses lower innovative capacity and without perfect knowledge spillovers between the regions, it can be shown that the ratio between the number of innovations in Region $s$ and Region $n$ tends to zero. A proof is available upon request. Moreover, in the context of our model, R\&D is assumed to push out the world technological frontier; i.e., we abstract from reverse engineering and duplicative research in developing countries.

20. This could be incorporated explicitly into a model with oligopolistic competition, where the patent holder competes with one or several imitators. However, our modeling approach captures the essence of declining expected profits for the patent holder when IPR enforcement becomes weaker, and it avoids tedious calculations implied by a setup with oligopolistic competition.

21. As our explicit focus is on IPR enforcement, we assume that each innovation obtains a patent of infinite length and neglect the issue of patent breadth. The typical patent length in most countries is 20 years, whereas the average legislative term of governments is four years. Hence, an alternative but analytically more tedious approach would assume a finite patent length and probabilistic enforcement of the patent (reflected by $\omega_{j t}$ ) only during this time span. As long as the duration of the patent is longer than the legislative term of the politician, which reflects reality as argued previously, our results will not be affected qualitatively by such an alternative modeling approach. However, a static model where both patent length and the legislative term of the government comprise only one period would imply full commitment to IPR policy on the side of the government. This would change some of our results, such as an inverted U-shaped relation between IPR enforcement and the innovative strength of an economy. 


\section{ANDREAS SCHÄFER AND MAIK T. SCHNEIDER}

22. Notice that for $\omega_{j, t}=1$, i.e., full patent protection, we obtain the standard Romer (1990) production function: $Y_{j, t}=A_{j} L_{j}^{1-\alpha} N_{t}(\underbrace{\alpha^{1 /(1-\alpha)} x_{c, j}}_{x_{m, j}})^{\alpha}$. The case without patent protection, $\omega_{j, t}=0$,

yields the highest possible output from a static perspective: $Y_{j, t}=A_{j} L_{j}^{1-\alpha} N_{t} x_{c, j}^{\alpha}$. Of course, this undermines incentives to invest in R\&D. In contrast to Bretschger and Steger (2013), we abstract from stochastic production. Moreover, we do not include a link between the intensity at which intermediate goods are used in production and aggregate factor productivity as in Moro (2012).

23. The assumption that both research productivity (or human capital) and the current technology stock play a positive role in innovative output and are complementary to a certain extent is standard in the literature. For example, in Romer (1990, p. 86), the aggregate stock of designs evolves according to $\dot{A}=\delta_{a} H_{A} A$, where $A$ is the stock of designs, $H_{A}$ is human capital, and $\delta_{a}$ is a productivity parameter. The assumption of decreasing returns on the firm and industry levels with respect to R\&D expenditures has been supported empirically, e.g., by Pakes and Griliches (1984) and Hall et al. (1988). On the macro level, probably the most important source of decreasing returns to R\&D can be seen in an increased probability of duplicative research through an increasing number of both rivals and expenditures, even though the R\&D process as such may be driven by large spillovers [Kortum (1993); Amir (2000); Klette and Kortum (2004)]. On a related line of argument, it is possible to think of plausible limits in transforming an ever-increasing stock of new ideas into usable knowledge for production [Weitzman (1998)]. From an aggregate perspective, decreasing returns may also reflect heterogeneity in the cost of research projects. A similar argument can be found in Scotchmer (2004a, Ch. 11). Convex costs of $\mathrm{R} \& \mathrm{D}$ are also widely used in the industrial-organization-type literature on IPR protection [see, e.g., Chin and Grossman (1990); McCalman (2002); Lai and Qiu (2003)]. In our model, R\&D improves total factor productivity rather than investment-specific productivity, which is in line with Rodriguez-Lopez and Torres (2012), who study the technological sources of productivity growth in Germany, Japan, and the United States. We do not consider the incentives that developed countries may have for improving developing country technologies, as investigated by Fernandes and Kumar (2007).

24. Schmookler (1966) emphasized that "the amount of invention is governed by the extent of the market"; see also the discussion in Acemoglu (2009, Chs. 12 and 15.5). In this way, our R\&D specification is subject to a scale effect in the sense that the size of the population affects the size of markets but not directly R\&D inputs such as research personnel or, in our particular case, lab equipment. If we assumed instead decreasing returns in research output with respect to the existing stock of knowledge following, e.g., Jones (1995), IPR enforcement would likely affect transitory growth and the steady-state level of output.

25. Consequently, the expected value of an invention can be written as

$$
E_{t}=\sum_{\tau=t+1}^{\infty} \beta^{\tau-t} P\left(\lambda_{n} \omega_{n, \tau}+\lambda_{s} \omega_{s, \tau}\right)
$$

26. Oudiz and Sachs (1985) argue that restricting the planning horizon of the government as we do here is a natural way to incorporate short-sightedness of governments into dynamic macroeconomic models. Our particular modeling choice regarding the planning horizon of the government could be motivated via short-lived households (with two-period lives). A minority of the households are altruistic and entertain research labs. At the cost of further complexity, we could interpret output $Y$ as sophisticated machinery that can be used either in research or to produce the consumption good via technology $F\left(L^{u}, Y\right)$, where $L^{u}$ denotes unskilled labor. Under the assumption that unskilled workers constitute the nonaltruistic (short-sighted) majority and $L^{u}$ and $Y$ are complements, there exists a conflict between R\&D expenditures and machinery for the production of the consumption good. Concerning IPR policy, a reelection-motivated government would then adopt the short-sighted view of the majority of unskilled workers.

27. The costs of IPR protection in our model consist of the associated deadweight loss in the consumption-good market. Additionally including resource-using IPR protection would increase these 
costs without changing the qualitative results. To keep the complexity of the model at a minimum, we abstracted from costs of IPR protection beyond deadweight losses.

28. More precisely, if $\Omega_{t+2}$ is identical in each period $t$, the governments' problems will be the same in every period and yield a unique solution regarding $\omega_{t+1}$. Rational expectations then imply that these unique solutions to the governments' problems are contained in $\Omega_{t+2}$. Hence, under Assumption 1 , there is a unique steady state with rational and stationary expectations. Given these expectations, the growth rate of the technology stock will immediately jump to its steady-state level. This is the equilibrium that we focus on in our analysis. Moreover, any transitional dynamics of the technology stock would result from transitional dynamics in the expectations on future IPR protection $\Omega_{t+2}$. A formal characterization of the stability of the steady state can be found in the working paper version [Schäfer and Schneider (2013)].

29. We suppress time indices for steady-state variables. The first-order condition is $R^{s}\left(\omega_{n}, \omega_{s}\right)=$ $\left(1+\frac{E_{t}}{2 \delta}\right)(D-P)+\frac{\beta \lambda_{s} P}{2 \delta}\left[Z+\omega_{s, t+1}(D-P)\right]=0$.

30. Note that the South's level of IPR enforcement may be perfect, that is, $\omega_{s}=1$. This can be the case if either $\Delta$ is sufficiently low, i.e., the research productivity in the North relative to the effective world market is high, or the relative size of the effective market in the South is very large, implying a low value of $\lambda_{n} / \lambda_{s}$. Further notice that positive consumption levels at any feasible level of IPR enforcement require $Z>P-D$. Consequently, the first term in brackets in (10) is greater than 1 (i.e., $\left.\frac{Z}{D-P}<-1\right)$.

31. Note that, by assumption, the marginally higher IPR enforcement applies to all active patents in $t+1, N_{t+1}$. This includes all innovations created before time $t, N_{t}$, as well as those invented in period $t, N_{t} \frac{E_{t}}{2 \delta}$.

32. A formal proof can be found in Appendix A.2.

33. For example, an increase in the North's market size leaving that of the South unaffected would increase both the world market size and the relative market size of North. Consequently, the effect on the IPR enforcement level would be a combination of the two effects. For this reason, it seems natural to isolate the resulting effects from each other.

34. This claim is verified analytically in the proof of Proposition 3.

35. For convenience we multiply $R_{n}\left(\omega_{n}, \omega_{s}\right)$ by $\Delta$ and then take the derivative with respect to $\Delta$. We obtain that $\partial R_{n}\left(\omega_{n}, \omega_{s}\right) / \partial \Delta<0$ if and only if

$$
D+\frac{\beta P}{2 \Delta} \frac{\tilde{E}^{2}}{4 \Delta^{2}}<0 .
$$

Note that $\Delta R_{n}\left(\omega_{n}, \omega_{s}\right)=0$ and $R_{n}\left(\omega_{n}, \omega_{s}\right)=0$ yield the same reaction functions $\omega_{n}\left(\omega_{s}\right)$. As $\tilde{E}^{2}$ depends on $\omega_{n}$ and $\omega_{s}$, we can solve for $\omega_{n}$ and obtain that $\partial R_{n}\left(\omega_{n}, \omega_{s}\right) / \partial \Delta<0$ if and only if $\omega_{n}<\omega_{n}^{c}\left(\omega_{s}\right)$, where

$$
\omega_{n}^{c}\left(\omega_{s}\right)=\frac{2 \lambda \Delta}{\beta P \lambda_{n}} \frac{1-\beta}{\beta} \sqrt{-\frac{2 \Delta}{\beta P} D}-\frac{\lambda_{s}}{\lambda_{n}} \omega_{s} .
$$

As $\omega_{n}^{c}\left(\omega_{s}\right)$ is a linear and declining function, it may intersect the North's reaction function at most twice. In Figure 2, we illustrate the case with one intersection. In response to a decrease in $\Delta$, the part of the North's reaction function that lies below $\omega_{n}^{c}\left(\omega_{s}\right)$ shifts to the upper right, whereas the part above $\omega_{n}^{c}\left(\omega_{s}\right)$ shifts to the lower left.

36. A proof is provided upon request.

37. In the formal bargaining problem, the governments' most preferred IPR enforcement levels are the points on the boundary of the feasible set that will realize if the respective regional government possesses all the bargaining power. The threat point of the problem is the decentralized equilibrium as described in the preceding section. How close to governments' ideal enforcement levels the bargaining outcome will be depends on the relative bargaining power, of course.

38. Remember that $\beta=\frac{1}{1+r}$.

39. Allowing for commitment over a longer finite time horizon would increase the desired levels of IPR protection but would not change the characteristics of the problem qualitatively. 
40. Note that we still assume that the government is able to adjust IPR enforcement after each period. Consequently, in period $t$, the South determines the optimal harmonized enforcement level $\omega_{s, t+1}^{h}$, taking as given the rational beliefs of the entrepreneurs about future governments' optimal decisions (see Assumption 1). The first-order condition reads as $\left(1+\frac{E_{t}^{h}}{2 \Delta}\right)(D-P)=-\beta \frac{P}{2 \Delta}\left[Z+\omega_{s, t+1}^{h}(D-P)\right]$.

41. The North's first-order condition reads $R_{n}^{h}\left(\omega_{n, t+1}^{h}\right)=\frac{E_{t}^{h}}{2 \lambda}(D-P)+\Delta\left(D+\frac{\lambda_{s}}{\lambda_{n}} P\right)+\frac{\beta P}{2}[Z+$ $\left.\omega_{n, t+1}^{h}\left(D+P \frac{\lambda_{s}}{\lambda_{n}}\right)-\frac{\left(E_{t+1}^{h}\right)^{2}}{4 \Delta \lambda \lambda_{n}}\right]=0$. As the North controls profit inflows from the South, the second-order condition for the problem described earlier may be violated, if $\frac{\lambda_{s}}{\lambda_{n}}$ is large enough so that the marginal gains from profit inflows to the North always overcompensate the marginal R\&D costs and deadweight losses in the North. Then the North opts for complete protection, $\omega_{n, t}^{h}=1, \forall t$. In the following, we consider the more interesting case where the second-order condition for a maximum is satisfied, such that $\frac{\lambda_{n}}{\lambda_{s}}>\frac{P-2 D}{P}>1$, because $D<0$.

42. Formally this can be seen as follows. As a direct consequence of the preceding arguments, it follows that the derivative of $R_{n}^{h}\left(\omega_{n}^{h}\right)$ with respect to $\lambda_{n} / \lambda_{s}$ is equivalent to the South's first-order condition in the steady state (cf. note 23 ),

$$
\frac{\partial R_{n}^{h}\left(\omega_{n}^{h}\right)}{\partial \frac{\lambda_{n}}{\lambda_{s}}}=R_{s}^{h}\left(\omega_{s}^{h}\right) \equiv\left(1+\frac{\tilde{E}^{h}}{2 \Delta}\right)(D-P)+\beta \frac{P}{2 \Delta}\left[Z+\omega_{j}^{h}(D-P)\right],
$$

with $j=n, s$. The optimal level of IPR enforcement of the South is given by $\partial R_{n}^{h}\left(\omega_{n}^{h}\right) / \partial\left(\lambda_{n} / \lambda_{s}\right)=$ $R_{s}^{h}\left(\omega_{s}^{h}\right)=0$. As (26) is decreasing with $\omega_{j}^{h}$, and given that $\Delta$ is such that the desired value of IPR enforcement of the North is higher than that of the South-i.e., $\omega_{n}^{h}>\omega_{s}^{h}$-an increase of the North's relative market size would imply $\partial R_{n}^{h}\left(\omega_{n}^{h}\right) / \partial\left(\lambda_{n} / \lambda_{s}\right)<0$ and thus $d \omega_{n}^{h} / d\left(\lambda_{n} / \lambda_{s}\right)<0$. This argument follows directly from the implicit-function theorem. The opposite holds true if $\omega_{n}^{h}<\omega_{s}^{h}$ (see Figure 4).

43. Recall that $\hat{\omega}_{n}^{h} \equiv \max \left\{\min \left\{\omega_{n}^{h}, 1\right\}, 0\right\}$. Moreover, we changed the set of parameters of interior solutions for illustrative purposes without altering the qualitative results. The set of parameters employed in the preceding section violates the second-order condition of the North, so that the North would choose full protection, i.e., $\omega_{n}^{h}=1$. The parameters used in this section imply a corner solution in the decentralized enforcement game, so that the South opts very fast for zero protection and the North behaves as in autarky.

44. Scotchmer (2004a, pp. 336 and 346) notes that during the TRIPS negotiations countries with smaller markets were in favor of stronger protection.

45. An equivalent result is obtained by Grossman and Lai (2004).

46. Intuitively, in the former case the motive of gaining profit flows from the South dominates, whereas in the latter $\Delta$ is so small that increased R\&D expenditures are of greater concern.

47. The reason is that if $\lambda_{n}=\lambda$, the decision problem of the North is entirely described by the constrained efficient problem.

48. In this case both $\omega_{n}^{e}$ and $\omega_{n}^{h}$ decline with $\lambda_{s} / \lambda_{n}$. Conditions under which $\omega_{n}^{e}<\omega_{n}^{h}$ for all $\Delta \geq \bar{\Delta}$ will be provided upon request.

49. As can be inferred directly from (6), the steady-state growth rate can be written as $g\left(\omega_{j}^{h}\right)=$ $\tilde{E} / 2 \Delta$

50. This can be the case when $\lambda_{s} / \lambda_{n}$ is large but still satisfies (14)]. Using the set of parameters employed in this section, we obtain $\omega_{s}^{e}=0$ (even for $\Delta<\bar{\Delta}$ ). The North behaves as in autarky where $\omega_{n}^{e}<\omega^{p}<\omega_{n}^{h}$ for $\Delta>\bar{\Delta}=0.005$. The resulting growth rate per year for $\Delta=0.009$, implying $\omega_{n}^{e} \approx 0.85$ and $\omega_{s}^{h} \approx 0.75$, equals $g^{e} \approx 3.6 \%$ and $g\left(\omega_{s}^{h}\right) \approx 3.8 \%$.

51. See, e.g., Lai and Qiu (2003).

52. We do not consider welfare effects in the North, which are very intuitive: The implementation of $\omega_{s}^{h}$ in the North causes welfare losses there relative to the implementation of $\omega_{n}^{h}$, because the South neglects the impact of $\omega_{s}^{h}$ on R\&D expenditures and profit inflows to the North.

53. We use the same set of parameters as before: $\alpha=0.3 ; \beta=0.4 ; \lambda=1 ; \lambda_{n}=0.78$. Details on the calculations can be obtained upon request. 
54. Note that $\omega_{s}^{f}$ must satisfy the first-order condition

$$
\frac{2 \delta}{P}\left(1+\frac{\tilde{E}}{2 \Delta}\right)(D-P)+\sum_{\tau=t+1}^{\infty} \beta^{\tau-t}(1+g)^{\tau-t-1} \lambda_{s}\left[Z+\omega_{s}^{f}(D-P)\right]=0
$$

The first-order condition concerning the (one-shot) full-commitment problem differs from the one with limited commitment (18) with respect to the second summand, which represents the discounted benefit of a change in IPR enforcement for all future periods. It follows that the South would prefer a higher harmonized enforcement level when full commitment was available-i.e., $\bar{W}_{s}\left(\omega_{s}^{f}\right)>\bar{W}_{s}\left(\omega_{s}^{h}\right)$.

55. Note that for $\bar{\Delta}$, where $\omega_{s}^{h}=\omega_{n}^{h}>0$, we have $\bar{W}_{s}^{n h}=\bar{W}_{s}^{s h}$. As the full-commitment solution of the South involves $\omega_{s}^{f}>\omega_{s}^{h}$ for all $\Delta$ where $\omega_{s}^{h}>0$, we must have $\bar{W}_{s}^{n h}>\bar{W}_{s}^{s h}$ for at least a small range of values $\Delta>\bar{\Delta}$, as there $\omega_{n}^{h}>\omega_{s}^{h}$ with $\omega_{n}^{h}$ and $\omega_{s}^{h}$ arbitrarily close because of the continuity of $\omega_{n}^{h}$ and $\omega_{s}^{h}$ in $\Delta$. Regarding all values $\Delta>\Delta_{f}^{0}$, we clearly obtain $\bar{W}_{s}^{n h} \leq \bar{W}_{s}^{s h}$. Consequently, there exists a cutoff value $\Delta_{w s}$ where for all $\bar{\Delta}<\Delta<\Delta_{w s}$ we have $\bar{W}_{s}^{n h}>\bar{W}_{s}^{s h}$. In the case depicted in Figure 6, the cutoff is unique, implying that for all $\Delta>\Delta_{w s}$, we have $\bar{W}_{s}^{n h} \leq \bar{W}_{s}^{s h}$. Because, for all $\Delta<\bar{\Delta}$, we have $\omega_{s}^{h}>\omega_{n}^{h}$, implying that $\bar{W}_{s}^{n h}<\bar{W}_{s}^{s h}$, there will be no such cutoff as $\Delta_{w s}$ for $\Delta$-values smaller than $\bar{\Delta}$.

56. Note that this is possible because $\omega_{s}\left(\omega_{n}\right)$ is a bijection.

57. Details on how $\omega_{n}^{x}$ is derived can be found in the extended appendix of Schäfer and Schneider (2013).

58. This follows from the facts mentioned previously: that $R_{n}^{e}\left(\omega_{n}\right)$ possesses two real roots and $\omega_{n}^{x}$ is the larger of the two.

\section{REFERENCES}

Acemoglu, Daron (2009) Introduction to Modern Economic Growth. Princeton, NJ: Princeton University Press.

Amir, Rabah (2000) Modelling imperfectly appropriable R\&D via spillover. International Journal of Industrial Organization 18, 1013-1032.

Borota, Teodora (2012) Innovation and imitation and a model of north-south trade. Journal of International Economics 87, 365-376.

Branstetter, Lee, Raymond Fisman, and C. Fritz Foley (2006) Do stronger intellectual property rights increase international technology transfer? Empirical evidence from U. S. firm-level panel data. Quarterly Journal of Economics 121, 321-349.

Bretschger, Lucas and Thomas Steger (2013) Globalization, the volatility of intermediate goods prices, and economic growth. Macroeconomic Dynamics 17, 402-430.

Chen, Yongmin and Thitima Puttitanun (2005) Intellectual property rights and innovation in developing countries. Journal of Development Economics 78, 474-493.

Chin, Judith C. and Gene M. Grossman (1990) Intellectual property rights and north-south trade. In Ronald W. Jones and Anne O. Krueger (eds.), The Political Economy of International Trade: Essays in Honor of Robert E. Baldwin, pp. 90-107. Cambridge, MA: Basil Blackwell.

Cychosz, Allison (2003) The effectiveness of international enforcement of intellectual property rights. John Marshall Law Review 37, 985-1016.

Deardorff, Allen V. (1992) Welfare effects of global patent protection. Economica 59, 35-51.

Dinopoulos, Elias and Paul Segerstrom (2007) North-South Trade and Economic Growth. Working paper, Stockholm School of Economics. Available at http://www.hhs.se/personal/Segerstrom.

Dinopoulus, Elias and Paul Segerstrom (2010) Intellectual property rights, multinational firms and economic growth. Journal of Development Economics 92, 13-27.

Diwan, Ishac and Dani Rodrik (1991) Patents, appropriate technology, and north-south trade. Journal of International Economics 30, 27-47. 


\section{8}

Drazen, Michael (2000) Political Economy in Macroeconomics. Princeton, NJ: Princeton University Press.

Eicher, Theo and Cecilia Garcia-Penalosa (2008) Endogenous strength of intellectual property rights: Implications for economic development and growth. European Economic Review 52, 237-258.

EU Commission (2008) The Anti-Counterfeiting Trade Agreement (ACTA): Fact Sheet. EU Commission, Brussels.Available at http://trade.ec.europa.eu/doclib/html/140836.htm.

EU Commission (2009) IPR Enforcement Report. SEC(2009) 1360, EU Commission, Brussels.

EU Commission (2012) The Anti-Counterfeiting Trade Agreement (ACTA): Questions and Answers. EU Commission, Brussels. Available at http://ec.europa.eu/trade/tackling-unfair-trade /acta/questions-and-answers/.

European Parliament (2004) Directive 2004/48/EC on the Enforcement of Intellectual Property Rights. European Parliament. Available at http://eur-lex.europa.eu/LexUriServ/LexUriServ.do? uri=CELEX:32004L0048:EN:NOT.

Fernandes, Ana and Krishna B. Kumar (2007) Inappropriate technology. What is in it for the rich? Macroeconomic Dynamics 11, 487-518.

Gersbach, Hans (2004) Competition of politicians for incentive contracts and elections. Public Choice 121, 157-177.

Ginarte, Juan C. and Walter G. Park (1997) Determinants of patent rights: A cross-national study. Research Policy 26, 283-301.

Grinols, Earl and Hwan C. Lin (2006) Global patent protection: Channels of north and south welfare gain. Journal of Economic Dynamics and Control 30, 205-227.

Grossman, Gene M. and Edwin C. Lai (2004) International protection of intellectual property. American Economic Review 94, 1635-1653.

Hall, Brownian, Zvi Griliches, and Jerry A. Hausman (1988) Patents and R\&D: Is there a lag? International Economic Review 27, 265-283.

Helpman, Elhanan (1993) Innovation, imitation, and intellectual property rights. Econometrica 61, 1247-1280.

Iwaisako, Tatsuro, Hitoshi Tanaka, and Koichi Futagami (2011) A welfare analysis of global patent protection in a model with endogenous innovation and foreign direct investment. European Economic Review 55, 1137-1151.

Jones, Charles I. (1995) R\&D-based models of economic growth. Journal of Political Economy 1003, 759-784.

Kiedaisch, Christian (2009) Patent Policy and Income Distribution. SSRN working paper. Available at http://ssrn.com/abstract=1600069 or http://dx.doi.org/10.2139/ssrn.1600069.

Klette, Tor J. and Samuel Kortum (2004) Innovating firms and aggregate innovation. Journal of Political Economy 112, 986-1018.

Kortum, Samuel (1993) Equilibrium R\&D and the patent-R\&D ratio: U.S. evidence. AEA Papers and Proceedings 83, 450-475.

Kwan, Yum K. and Edwin C. Lai (2003) Intellectual property rights protection and endogenous economic growth. Journal of Economic Dynamics and Control 27, 853-873.

Lai, Edwin C. (1998) International intellectual property rights protection and the rate of product innovation. Journal of Development Economics 55, 133-153.

Lai, Edwin C. and Larry D. Qiu (2003) The north's intellectual property rights standard for the south? Journal of International Economics 59, 183-209.

Maskus, Keith E. (1990) Normative concerns in the international protection of intellectual property rights. World Economy 13, 387-409.

Maskus, Keith E. (2000) Intellectual Property Rights in the Global Economy. Washington, DC: Peterson Institute for International Economics.

Maskus, Keith E. (2012) Private Rights and Public Problems: The Global Economics of Intellectual Property in the 21st Century. Washington, DC: Peterson Institute for International Economics.

McCalman, Phillip (2001) Reaping what you sow: An empirical analysis of international patent harmonization. Journal of International Economics 55, 161-186. 
McCalman, Phillip (2002) National patents, innovation and international agreements. Journal of International Trade and Economic Development 11, 1-14.

Moro, Alession (2012) Biased technical change, intermediate goods, and total factor productivity. Macroeconomic Dynamics 16, 184-203.

Müller, Markus (2007) Motivation of politicians and long-term policies. Public Choice 132, 273-289.

Nordhaus, William D. (1969) Invention, Growth and Welfare: A Theoretical Treatment of Technological Change. Cambridge, MA: MIT Press.

OECD (2009) Magnitude of Counterfeiting and Piracy of Tangible Products: An Update. OECD Project on Counterfeiting and Piracy. Available at http://www.oecd.org/dataoecd/57/27/44088872.pdf.

Office of U.S. Trade Representative (2010) Special 301 Report. Office of U.S. Trade Representative.

Oudiz, Gilles and Jeffrey Sachs (1985) International policy coordination in dynamic macroeconomic models. In Willem H. Buiter and Richard C. Marston (eds.), International Economic Policy Coordination, pp. 274-230. Cambridge, UK: Cambridge University Press.

Pakes, Ariel and Zvi Griliches (1984) Patents and R\&D at the firm level: A first look. In Zvi Griliches (ed.), $R \& D$, Patents, and Productivity, pp. 55-72. Chicago: University of Chicago Press.

Parello, Carmelo (2008) A north-south model of intellectual property rights protection and skill accumulation. Journal of Development Economics 85, 253-281.

Persson, Torsten and Guido Tabellini (2000) Political Economics: Explaining Economic Policy. Cambridge, MA: MIT Press.

Reuters (2010) Countries Reach Tentative Anti-counterfeiting Pact. Reuters article 2010/10/02. Available at http://www.reuters.com/article/2010/10/02/ us-trade-counterfeiting -idUSTRE6910AO20101002.

Rodriguez-Lopez, Jesus and Jose L. Torres (2012) Technological sources of productivity growth in Germany, Japan, and the United States. Macroeconomic Dynamics 16, 133-150.

Romer, Paul M. (1990) Endogenous technological change. Journal of Political Economy 98, 71-102.

Sakakibara, Mariko and Lee Branstetter (2001) Do stronger patents induce more innovation? Evidence from the 1988 Japanese patent law reforms. RAND Journal of Economics 32, 77-100.

Schäfer, Andreas and Maik T. Schneider (2013) Endogenous Enforcement of Intellectual Property, North-South Trade, and Growth. SSRN working paper 1907231.

Schmookler, Jacob (1966) Invention and Growth. Cambridge, MA: Harvard University Press.

Scotchmer, Suzanne (2004a) Innovation and Incentives. Cambridge MA: MIT Press.

Scotchmer, Suzanne (2004b) The political economy of intellectual property treaties. Journal of Law, Economics, and Organization 20, 415-437.

Weitzman, Martin L. (1998) Recombinant growth. Quarterly Journal of Economics 113, 331-360.

\section{APPENDIX}

\section{A.1. PROOF OF LEMMA 1}

(i) As $R_{n}\left(\omega_{n}, \omega_{s}\right)$ is a quadratic function of $\omega_{n}$, we obtain two roots when solving $R_{n}\left(\omega_{n}, \omega_{s}\right)=0$ for $\omega_{n}$. We denote these two roots by $\omega_{n 1}$ and $\omega_{n 2}$ :

$$
\begin{aligned}
& \omega_{n 1}\left(\omega_{s}\right)=\frac{1}{\beta^{2} P^{2} \lambda_{n}}\left[G\left(\omega_{s}\right)+2 \sqrt{\Delta \lambda H\left(\omega_{s}\right)}\right], \\
& \omega_{n 2}\left(\omega_{s}\right)=\frac{1}{\beta^{2} P^{2} \lambda_{n}}\left[G\left(\omega_{s}\right)-2 \sqrt{\Delta \lambda H\left(\omega_{s}\right)}\right],
\end{aligned}
$$


where

$$
\begin{aligned}
G\left(\omega_{s}\right)= & -\beta^{2} \lambda_{s} P^{2} \omega_{s}-2(1-\beta) \Delta \lambda[-(2-\beta) D+P]<0, \\
H\left(\omega_{s}\right)= & \Delta \lambda\left\{\left(2-3 \beta+\beta^{2}\right)^{2} D^{2}+(1-\beta)^{2}\left[P^{2}-4(1-\beta) D P\right]\right\} \\
& +(1-\beta)^{2} \beta^{2} P^{2}\left[\lambda_{n} Z-\lambda_{s}(D-P) \omega_{s}\right]>0 .
\end{aligned}
$$

The signs of $G\left(\omega_{s}\right)$ and $H\left(\omega_{s}\right)$ imply that $\omega_{n 2}\left(\omega_{s}\right)$ is negative for all values $\omega_{s} \geq 0$. In contrast, $\omega_{n 1}\left(\omega_{s}\right)$ can be positive. Hence the latter is the only economically sensible solution and we define $\omega_{n}^{r}\left(\omega_{s}\right) \equiv \omega_{n 1}\left(\omega_{s}\right)$.

(ii) Taking the second derivative of $\omega_{n}^{r}\left(\omega_{s}\right)$ with respect to $\omega_{s}$ gives

$$
\frac{d^{2} \omega_{n}^{r}\left(\omega_{s}\right)}{d \omega_{s}^{2}}=-\frac{(1-\beta)^{4} \beta^{2} \Delta^{2} \lambda^{2} \lambda_{s}^{2}(D-P)^{2} P^{2}}{2 \lambda_{n}\left[H\left(\omega_{s}\right)\right]^{\frac{3}{2}}}<0, \quad \forall \omega_{s} \geq 0 .
$$

Note that $H\left(\omega_{s}\right)>0$ for all $\omega_{s} \geq 0$. Thus $\omega_{n}^{r}\left(\omega_{s}\right)$ is strictly concave.

To show that $\omega_{n}^{r}\left(\omega_{s}\right)$ is strictly decreasing on $[0,1]$, we use the implicit-function theorem. The partial derivative of $R_{n}\left(\omega_{n}, \omega_{s}\right)$ with respect to $\omega_{n}$ reads

$$
\frac{\partial R_{n}\left(\omega_{n}, \omega_{s}\right)}{\partial \omega_{n}}=\frac{1}{2} \frac{\partial \tilde{E}}{\partial \omega_{n}}(D-P)+\frac{\beta P}{2}\left(D-\frac{\tilde{E}}{2 \Delta} \frac{\partial \tilde{E}}{\partial \omega_{n}}\right)<0 .
$$

As the monopoly distortion $D$ is negative, the derivative is smaller than zero for all $\left(\omega_{n}, \omega_{s}\right) \in \mathbf{R}_{+}^{2}$. The derivative of $R_{n}\left(\omega_{n}, \omega_{s}\right)$ with respect to $\omega_{s}$ can be written as

$$
\frac{\partial R_{n}\left(\omega_{n}, \omega_{s}\right)}{\partial \omega_{s}}=-\frac{\beta^{2}}{1-\beta} \frac{P^{2} \lambda_{s}}{2 \lambda}+\frac{1}{2} \frac{\partial \tilde{E}}{\partial \omega_{s}}\left(D-\frac{\beta P}{2} \frac{\tilde{E}}{\Delta}\right)<0 .
$$

The implicit-function theorem then implies that

$$
\frac{d \omega_{n}}{d \omega_{s}}=-\frac{\frac{\partial R_{n}\left(\omega_{n}, \omega_{s}\right)}{\partial \omega_{n}}}{\frac{\partial R_{n}\left(\omega_{n}, \omega_{s}\right)}{\partial \omega_{s}}}<0 .
$$

\section{A.2. PROOF OF PROPOSITION 2}

The intuition of the proof can be summarized as follows. First, we show that there is a unique economically sensible intersection of the reaction functions of the North and the South. Then we verify that the reaction function of the North intersects the one of the South from below. This implies that there exists a stable "cobweb mechanism" toward the intersection of the reaction functions. This mechanism leads to a unique equilibrium that is the intersection of the reaction function itself if the intersection is in the feasible set. Otherwise it determines a unique equilibrium on the boundary of the feasible set.

(1) We show that there is a unique economically sensible intersection of the reaction functions of the North and the South.

Let us define $\underline{\omega}_{s}$ as the solution to $H\left(\omega_{s}\right)=0$, where $H\left(\omega_{s}\right)$ is given in the proof of Lemma 1. Because $H\left(\omega_{s}\right)>0, \forall \omega_{s} \geq 0$, we obtain $\underline{\omega}_{s}<0$ and that $\omega_{n}^{r}\left(\omega_{s}\right)$ is a real 
number for all $\omega_{s}>\underline{\omega}_{s}$. Further, $\omega_{n}^{r}\left(\omega_{s}\right)$ is strictly concave on $\left(\underline{\omega}_{s}, \infty\right)$ according to the proof of Lemma 1. Inserting $\omega_{s}^{r}\left(\omega_{n}\right)$ given by (10) into $R_{n}\left(\omega_{n}, \omega_{s}\right)$ yields $R_{n}^{e}\left(\omega_{n}\right)$. Solving $R_{n}^{e}\left(\omega_{n}\right)=0$ for $\omega_{n}$ gives

$$
\begin{aligned}
& \omega_{n 1}^{x}=\frac{1}{\beta^{2} P^{2} \lambda_{n}}\left[Q_{1}(\Delta)+2 \sqrt{(2-\beta)^{2} \Delta \lambda^{2} Q_{2}(\Delta)}\right], \\
& \omega_{n 2}^{x}=\frac{1}{\beta^{2} P^{2} \lambda_{n}}\left[Q_{1}(\Delta)-2 \sqrt{(2-\beta)^{2} \Delta \lambda^{2} Q_{2}(\Delta)}\right],
\end{aligned}
$$

where

$$
\begin{aligned}
& Q_{1}(\Delta)=\frac{\beta^{2} \lambda_{s} Z P^{2}}{D-P}+2 \Delta \lambda[(3-\beta)(2-\beta) D-(4-3 \beta) P]<0, \\
& Q_{2}(\Delta)=(3-\beta)^{2} \Delta D^{2}-4(3-2 \beta) \Delta D P+P^{2}\left[2(2-\beta) \Delta+\beta^{2} Z\right]>0 .
\end{aligned}
$$

Because $Q_{2}(\Delta)>0, R_{n}^{e}\left(\omega_{n}\right)$ possesses two real roots-i.e., the reaction functions $\omega_{n}^{r}\left(\omega_{s}\right)$ and $\omega_{s}^{r}\left(\omega_{n}\right)$ possess two intersections in the real plane. As $Q_{1}(\Delta)<0, \omega_{n 2}^{x}$ is strictly negative for all relevant parameter values and only $\omega_{n 1}^{x}$ possesses economic relevance. Hence, we have $\omega_{N}^{x}=\omega_{n 1}^{x}$.

Given a unique $\omega_{n}^{x}$, we can immediately infer from (10) that $\omega_{s}^{x}=\omega_{s}^{r}\left(\omega_{n}^{x}\right)$ is also unique.

(2) Now, we show that the reaction of the North intersects the one of the South from below.

We define $\bar{\omega}_{s} \equiv \omega_{s}^{r}\left(\omega_{n 2}^{x}\right)$ and the inverse of the South's reaction function ${ }^{56}$

$$
\omega_{n}^{s}\left(\omega_{s}\right)=(1-\beta)\left[\frac{Z}{D-P} \frac{\lambda_{s}}{\lambda_{n}}+\frac{2 \Delta}{\beta P} \frac{\lambda}{\lambda_{n}}\right]-(2-\beta) \frac{\lambda_{s}}{\lambda_{n}} \omega_{s} .
$$

Part (1) of the proof, together with strict concavity of $\omega_{n}^{r}\left(\omega_{s}\right)$ on $\left(\underline{\omega}_{s}, \infty\right)$ and $\omega_{n}^{s}\left(\omega_{s}\right)$ being a strictly decreasing linear function, yields the following lemma.

LEMMA 3. In the interval $\left(\underline{\omega}_{s}, \bar{\omega}_{s}\right), \omega_{n}^{r}\left(\omega_{s}\right)$ intersects $\omega_{n}^{s}\left(\omega_{s}\right)$ from below:

$$
\begin{array}{ll}
\omega_{n}^{r}\left(\omega_{s}\right)<\omega_{n}^{s}\left(\omega_{s}\right), & \text { if } \underline{\omega}_{s}<\omega_{s}<\omega_{s}^{x}, \\
\omega_{n}^{r}\left(\omega_{s}\right)>\omega_{n}^{s}\left(\omega_{s}\right), & \text { if } \omega_{s}^{x}<\omega_{s}<\bar{\omega}_{s} .
\end{array}
$$

(3) We have to show that

(i) if $\omega_{n}^{x} \leq 0$ and $\omega_{s}^{x} \leq 0$, the unique equilibrium is $\left(\omega_{n}, \omega_{s}\right)=\left(\hat{\omega}_{n}^{r}(0), 0\right)$.

(ii) if $\omega_{n}^{x} \leq 0$ and $\omega_{s}^{x} \in(0,1)$, the unique equilibrium is $\left(\omega_{n}, \omega_{s}\right)=\left(0, \hat{\omega}_{s}^{r}(0)\right)$.

(iii) if $\omega_{n}^{x} \leq 0$ and $\omega_{s}^{x} \geq 1$, the unique equilibrium is $\left(\omega_{n}, \omega_{s}\right)=\left(\hat{\omega}_{n}^{r}(1), \hat{\omega}_{s}^{r}(0)\right)$.

(iv) if $\omega_{n}^{x} \in(0,1)$ and $\omega_{s}^{x} \leq 0$, the unique equilibrium is $\left(\omega_{n}, \omega_{s}\right)=\left(\hat{\omega}_{n}^{r}(0), 0\right)$.

(v) if $\omega_{n}^{x} \in(0,1)$ and $\omega_{s}^{x} \in(0,1)$, the unique equilibrium is $\left(\omega_{n}, \omega_{s}\right)=\left(\omega_{n}^{x}, \omega_{s}^{x}\right)$.

(vi) if $\omega_{n}^{x} \in(0,1)$ and $\omega_{s}^{x} \geq 1$, the unique equilibrium is $\left(\omega_{n}, \omega_{s}\right)=\left(\hat{\omega}_{n}^{r}(1), 1\right)$.

(vii) if $\omega_{n}^{x} \geq 1$ and $\omega_{s}^{x} \leq 0$, the unique equilibrium is $\left(\omega_{n}, \omega_{s}\right)=\left(\hat{\omega}_{n}^{r}(0), \hat{\omega}_{s}^{r}(1)\right)$.

(viii) if $\omega_{n}^{x} \geq 1$ and $\omega_{s}^{x} \in(0,1)$, the unique equilibrium is $\left(\omega_{n}, \omega_{s}\right)=\left(1, \hat{\omega}_{s}^{r}(1)\right)$.

(ix) if $\omega_{n}^{x} \geq 1$ and $\omega_{s}^{x} \geq 1$, the unique equilibrium is $\left(\omega_{n}, \omega_{s}\right)=(1,1)$.

The existence of the equilibrium is established as follows. 
(i) Suppose that $\omega_{n}^{x} \leq 0$ and $\omega_{s}^{x} \leq 0$. Given $\omega_{s}=0$, the best response of North is $\hat{\omega}_{n}^{r}(0)$. Given $\omega_{n}=\hat{\omega}_{n}^{r}(0)$, we obtain $\omega_{s}^{r}\left(\omega_{n}^{r}(0)\right) \leq 0$ by using Lemma 3 and the fact that $\omega_{s}^{r}\left(\omega_{n}\right)$ is strictly declining. Consequently, the South's best response to $\omega_{n}=\hat{\omega}_{n}^{r}(0)$ is $\omega_{s}=0$.

(ii) Suppose that $\omega_{n}^{x} \leq 0$ and $\omega_{s}^{x} \in(0,1)$. Given $\omega_{s}=\hat{\omega}_{s}^{r}(0)$, then best response of North is 0 because $\omega_{n}^{r}\left(\hat{\omega}_{s}^{r}(0)\right) \leq 0$ as a result of $\omega_{s}^{r}\left(\omega_{n}\right)$ being a strictly declining function and Lemma 3. Given $\omega_{n}=0$, the South's best response is $\hat{\omega}_{s}^{r}(0)$.

(iii) Suppose that $\omega_{n}^{x} \leq 0$ and $\omega_{s}^{x} \geq 1$. We distinguish the cases where $\omega_{n}^{r}(1) \leq 0$ and $\omega_{n}^{r}(1)>0$. If $\omega_{n}^{r}(1) \leq 0$, the equilibrium can be written as $\left(\omega_{n}, \omega_{s}\right)=\left(0, \hat{\omega}_{s}^{r}(0)\right)$. $\omega_{n}^{r}(1) \leq 0$ together with Lemma 3 and $\omega_{s}^{r}\left(\omega_{n}\right)$ strictly declining implies that $\omega_{n}^{r}\left(\hat{\omega}_{s}^{r}(0)\right) \leq 0$. Hence, the best response of the North is $\omega_{n}=0$. Further, given $\omega_{n}=0, \hat{\omega}_{s}^{r}(0)$ is the best response of the South.

If $\omega_{n}^{r}(1)>0$, the equilibrium can be written as $\left(\omega_{n}, \omega_{s}\right)=\left(\hat{\omega}_{n}^{r}(1), 1\right)$. Given $\omega_{s}=1$, $\hat{\omega}_{n}^{r}(1)$ is the best response of the North. $\omega_{n}^{r}(1)>0$ together with Lemma 3 and $\omega_{s}^{r}\left(\omega_{n}\right)$ strictly declining imply that $\omega_{s}^{r}\left(\omega_{n}^{r}(1)\right) \geq 1$. Consequently, the South's best response is $\omega_{s}=1$.

(iv) Suppose that $\omega_{n}^{x} \in(0,1)$ and $\omega_{s}^{x} \leq 0$. Given $\omega_{s}=0$, the best response of the North is $\hat{\omega}_{n}^{r}(0)$. Given $\omega_{n}=\hat{\omega}_{n}^{r}(0), \omega_{s}^{r}\left(\omega_{n}^{r}(0)\right) \leq 0$ follows from Lemma 3 and $\omega_{s}^{r}\left(\omega_{n}\right)$ being a strictly declining function. Hence, the South's best response is $\omega_{s}=0$.

(v) Let $\omega_{n}^{x} \in(0,1)$ and $\omega_{s}^{x} \in(0,1)$. Then $\left(\omega_{n}, \omega_{s}\right)=\left(\omega_{n}^{x}, \omega_{s}^{x}\right)$ is an equilibrium by the definition of the reaction functions.

(vi) Let $\omega_{n}^{x} \in(0,1)$ and $\omega_{s}^{x} \geq 1$. Given $\omega_{s}=1$, the best response of the North is $\hat{\omega}_{n}^{r}(1)$. Given $\omega_{n}=\hat{\omega}_{n}^{r}(1)$, the South's best response is $\omega_{s}=1$, as $\omega_{s}^{r}\left(\omega_{n}^{r}(1)\right) \geq 1$ because of Lemma 3 and $\omega_{s}^{r}\left(\omega_{n}\right)$ being a strictly declining function.

(vii) Suppose that $\omega_{n}^{x} \geq 1$ and $\omega_{s}^{x} \leq 0$. We distinguish the cases where $\omega_{n}^{r}(0) \leq 1$ and $\omega_{n}^{r}(0)>1$. If $\omega_{n}^{r}(0) \leq 1$, the equilibrium can be written as $\left(\omega_{n}, \omega_{s}\right)=\left(\hat{\omega}_{n}^{r}(0), 0\right)$. Given $\omega_{s}=0, \hat{\omega}_{n}^{r}(0)$ is the best response of the North. Because of Lemma 3 and $\omega_{s}^{r}\left(\omega_{n}\right)$ being a strictly declining function, $\omega_{s}^{r}\left(\omega_{n}^{r}(0)\right) \leq 0$. Consequently, the South's best response is $\omega_{s}=0$.

If $\omega_{n}^{r}(0)>1$, the equilibrium can be written as $\left(\omega_{n}, \omega_{s}\right)=\left(1, \hat{\omega}_{s}^{r}(1)\right) . \omega_{n}^{r}(0)>1$, together with Lemma 3 and $\omega_{s}^{r}\left(\omega_{n}\right)$ being a strictly declining function, implies that $\omega_{n}^{r}\left(\hat{\omega}_{s}^{r}(1)\right) \geq 1$. Hence, the best response of the North is $\omega_{n}=1$. Further, given $\omega_{n}=1, \hat{\omega}_{s}^{r}(1)$ is the best response of the South.

(viii) Suppose that $\omega_{n}^{x} \geq 1$ and $\omega_{s}^{x} \in(0,1)$. Given $\omega_{s}=\hat{\omega}_{s}^{r}(1)$, Lemma 3 and $\omega_{s}^{r}\left(\omega_{n}\right)$ strictly declining imply that $\omega_{n}^{r}\left(\hat{\omega}_{s}^{r}(1)\right) \geq 1$. Consequently, the North's best response is $\omega_{n}=1$. Given $\omega_{n}=1$, the South's best response is $\omega_{s}=\hat{\omega}_{s}^{r}(1)$.

(ix) Let $\omega_{n}^{x} \geq 1$ and $\omega_{s}^{x} \geq 1$. Because both functions, $\omega_{n}^{r}\left(\omega_{s}\right)$ and $\omega_{n}^{s}\left(\omega_{s}\right)$, are declining on $\mathbf{R}_{+}, \omega_{n}^{x} \geq 1$ and $\omega_{s}^{x} \geq 1$ implies that $\omega_{n}^{r}\left(\omega_{s}\right), \omega_{n}^{s}\left(\omega_{s}\right) \geq 1$ for all $\omega_{s} \in[0,1]$ and $\omega_{s}^{r}\left(\omega_{n}\right) \geq 1$ for all $\omega_{n} \in[0,1]$. Consequently, given $\omega_{s}=1, \omega_{n}^{r}(1) \geq 1$, leading to $\omega_{n}=1$ as the best response of the North. Given $\omega_{n}=1$, the best response of the South is $\omega_{s}=1$ as $\omega_{s}^{r}(1) \geq 1$.

(4) Concerning uniqueness, Lemma 3 and the fact that $\omega_{s}^{r}\left(\omega_{n}\right)$ and $\omega_{n}^{s}\left(\omega_{s}\right)$ are strictly declining functions imply that $\forall \omega_{s} \in[0,1]$ and $\omega_{s} \neq \omega_{s}^{e}$, we have $\hat{\omega}_{s}^{r}\left(\hat{\omega}_{n}^{r}\left(\omega_{s}\right)\right) \neq \omega_{s}$. Further, $\forall \omega_{n} \in[0,1]$ and $\omega_{n} \neq \omega_{n}^{e}$, we obtain $\hat{\omega}_{n}^{r}\left(\hat{\omega}_{s}^{r}\left(\omega_{n}\right)\right) \neq \omega_{n}$. As a consequence, the equilibrium $\left(\omega_{n}, \omega_{s}\right)=\left(\bar{\omega}_{n}^{x}, \omega_{s}^{e}\right)$ as given in Proposition 2 is unique. 


\section{A.3. PROOF OF LEMMA 2}

From the proof of Proposition 2, we know that

$$
\omega_{n}^{x}=\frac{1}{\beta^{2} P^{2} \lambda_{n}}\left[Q_{1}(\Delta)+2 \sqrt{(2-\beta)^{2} \Delta \lambda^{2} Q_{2}(\Delta)}\right]
$$

where

$$
\begin{aligned}
& Q_{1}(\Delta)=\frac{\beta^{2} \lambda_{s} Z P^{2}}{D-P}+2 \Delta \lambda((3-\beta)(2-\beta) D-(4-3 \beta) P)<0, \\
& Q_{2}(\Delta)=(3-\beta)^{2} \Delta D^{2}-4(3-2 \beta) \Delta D P+P^{2}\left(2(2-\beta) \Delta+\beta^{2} Z\right)>0 .
\end{aligned}
$$

The second derivative of $\omega_{n}^{x}$ with respect to $\Delta$ reads

$$
\frac{d^{2} \omega_{n}^{x}}{d \Delta^{2}}=-\frac{(2-\beta) \beta^{2} P^{2} \lambda Z}{2 \lambda_{n} Q_{2}(\Delta)^{\frac{3}{2}}}<0 .
$$

Concerning the convexity of the South's IPR level in $\Delta$, we use equation (10) and take the second derivative with respect to $\Delta$ to obtain

$$
\frac{d^{2} \omega_{s}^{x}}{d \Delta^{2}}=-\frac{1}{2-\beta} \frac{\lambda_{n}}{\lambda_{s}} \frac{d^{2} \omega_{n}^{x}}{d \Delta^{2}}<0
$$

Because $d^{2} \omega_{n}^{x} / d \Delta^{2}<0, d^{2} \omega_{s}^{x} / d \Delta^{2}$ must be positive and hence $\omega_{s}^{x}$ is strictly convex in $\Delta$.

\section{A.4. PROOF OF PROPOSITION 3}

To verify the three items of Proposition 3 , it is necessary to show that $\omega_{s}^{x}$ is strictly convex and declining with $\Delta$, whereas $\omega_{n}^{x}$ is strictly concave and exhibits an inverted U-shaped relation with $\Delta$. Thus, determining the roots of $\omega_{s}^{x}$ and $\omega_{n}^{x}$ in $\Delta$ identifies $\Delta_{s}^{0}$ and $\Delta_{n}^{0}$. Comparing $\Delta_{s}^{0}$ and $\Delta_{n}^{0}$ yields condition (14).

Item (i) of Proposition 3 follows from the properties of $\omega_{s}^{x}$ mentioned previously. For item (ii), it is also necessary to show that $\omega_{n}^{r}(0)$ (i.e., the North's IPR enforcement level in autarky) is strictly concave in $\Delta$ and intersects $\omega_{n}^{x}$ from above at $\Delta^{0}\left(\equiv \Delta_{s}^{0}\right)$. Because $\omega_{n}^{e}$ is identical to $\omega_{n}^{x}$ for all $\Delta<\Delta^{0}$ and identical to $\omega_{n}^{r}(0)$ for all $\Delta \geq \Delta^{0}$, this implies that $\omega_{n}^{e}$ is strictly concave and shows an inverted $U$-shape over the entire relevant interval, but is - of course-not differentiable at $\Delta^{0}$. Item (iii) follows from the properties of $\omega_{n}^{x}$ and $\omega_{s}^{x}$ given that condition (14) is satisfied.

The detailed formal proof becomes involved because $\omega_{n}^{x}$ and $\omega_{s}^{x}$ do not possess closed forms that meaningfully reveal their properties in $\Delta$. This makes it necessary to operate via the first-order conditions using the implicit-function theorem and making several estimates. The detailed formal proof is provided in the working paper version [Schäfer and Schneider (2013)]. 


\section{A.5. PROOF OF PROPOSITION 4}

The equilibrium growth rate of both economies is

$$
g=\frac{\beta P\left(\frac{\lambda_{n}}{\lambda} \omega_{n}^{x}+\frac{\lambda_{s}}{\lambda} \omega_{s}^{x}\right)}{2(1-\beta) \Delta}
$$

Inserting $^{57}$

$$
\omega_{n}^{x}=\frac{1}{\beta^{2} P^{2} \lambda_{n}}\left[Q_{1}(\Delta)+2 \sqrt{(2-\beta)^{2} \Delta \lambda^{2} Q_{2}(\Delta)}\right]
$$

and $\omega_{s}^{x}$ as given by (10) and differentiating with respect to $\Delta$ yields

$$
\frac{d g}{d \Delta}=\frac{-\beta Z}{2 \Delta \sqrt{\Delta\left(\beta^{2} Z P^{2}+\Delta\left((3-\beta)^{2} D^{2}-4(3-2 \beta) D P+2(2-\beta) P^{2}\right.\right.}}<0 .
$$

\section{A.6. PROOF OF PROPOSITION 5}

First we show that $\omega_{n}^{x}$ increases with $\lambda_{n} / \lambda_{s}$ and thereafter that $\omega_{s}^{x}$ decreases with $\lambda_{n} / \lambda_{s}$. Finally, we verify that the growth rate is invariant with $\lambda_{n} / \lambda_{s}$ given $\Delta$.

1. Let us consider $R_{n}^{e}\left(\omega_{n}\right)$, which is derived by inserting $\omega_{s}^{r}\left(\omega_{n}\right)$ as given by (10) into the first-order condition of the North (13). As shown in the first part of the proof of Proposition 2, $R_{n}^{e}\left(\omega_{n}\right)$ possesses two real roots, of which only the larger one is economically sensible and is denoted by $\omega_{n}^{x}$. Using the implicit-function theorem, we obtain

$$
\left.\frac{d \omega_{n}^{x}}{d\left(\lambda_{n} / \lambda_{s}\right)}\right|_{\lambda}=\left.\frac{d \omega_{n}^{x}}{d \lambda_{n}}\right|_{\lambda}=-\frac{\left.\frac{\partial R_{n}^{e}\left(\omega_{n}\right)}{\partial \lambda_{n}}\right|_{\lambda}}{\frac{\partial R_{n}^{e}\left(\omega_{n}\right)}{\partial \omega_{n}}}
$$

Concerning the sign of the denominator, we can show that $\partial R_{n}^{e}\left(\omega_{n}\right) /\left.\partial \omega_{n}\right|_{\omega_{n}=\omega_{n}^{x}}<0$ by verifying that $R_{n}^{e}\left(\omega_{n}\right)$ is strictly concave. ${ }^{58} R_{n}^{e}\left(\omega_{n}\right)$ can be written as

$$
\begin{aligned}
& R_{n}^{e}\left(\omega_{n}\right)=\frac{D-P}{2} \frac{\beta}{2-\beta} P\left(\frac{\lambda_{n}}{\lambda} \omega_{n}-A_{1}\right)+\Delta D \\
& +\frac{\beta P}{2}\left[\frac{\lambda_{n}}{\lambda}\left(Z+\omega_{n} D\right)-P \frac{1-\beta}{2-\beta} A_{1}-P \frac{\lambda_{n}}{\lambda} \frac{\omega_{n}}{2-\beta}\right. \\
& \left.-\left(\frac{\beta}{2-\beta}\right)^{2} \frac{P^{2}}{4 \Delta}\left(\frac{\lambda_{n}}{\lambda} \omega_{n}-A_{1}\right)^{2}\right] .
\end{aligned}
$$

where $A_{1}=\frac{Z}{D-P} \frac{\lambda_{s}}{\lambda}+\frac{2 \Delta}{\beta P}$. Taking the second derivative with respect to $\omega_{n}$, we obtain

$$
\frac{\partial^{2} R_{n}^{e}\left(\omega_{n}\right)}{\partial \omega_{n}^{2}}=-\left(\frac{\beta}{2-\beta}\right)^{2} \frac{P^{2}}{2 \Delta}\left(\frac{\lambda_{n}}{\lambda}\right)^{2}<0 .
$$


As a consequence of the denominator being negative, the sign of $d \omega_{n}^{x} /\left.d \lambda_{n}\right|_{\lambda}$ is identical to that of $d R_{n}^{e}\left(\omega_{n}\right) /\left.d \lambda_{n}\right|_{\lambda}$. For the derivative of $R_{n}^{e}\left(\omega_{n}\right)$ with respect to $\lambda_{n}$ given the total market size $\lambda$, we can write

$$
\begin{aligned}
\left.\frac{\partial R_{n}^{e}\left(\omega_{n}\right)}{\partial \lambda_{n}}\right|_{\lambda}= & \frac{\beta P\left(Z+\omega_{n}(D-P)\right)}{4 \Delta(2-\beta)^{2} \lambda^{2}(D-P)^{2}}[2 \Delta \lambda(D-P)((3-\beta)(2-\beta) D \\
& \left.-(4-3 \beta) P)+\beta^{2} P^{2}\left(\lambda_{s} Z-\lambda_{n} \omega_{n}(D-P)\right)\right] .
\end{aligned}
$$

Because $Z+D-P>0$, it can readily be observed from (A.6) that $d R_{n}^{e}\left(\omega_{n}\right) /\left.d \lambda_{n}\right|_{\lambda}>$ 0 . Hence, if we have an interior solution where $\omega_{n}^{e} \in(0,1)$, the North's IPR enforcement level strictly increases with its relative effective market size.

2. We insert $\lambda_{s}=\lambda-\lambda_{n}$ into (10) and take the derivative with respect to $\lambda_{n}$ given the total market size $\lambda$. We obtain

$$
\left.\frac{d \omega_{s}^{x}}{d \lambda_{n}}\right|_{\lambda}=-\frac{1-\beta}{2-\beta} \frac{2 \Delta \lambda}{\lambda_{s}^{2}}-\frac{\omega_{n}}{2-\beta} \frac{\lambda}{\lambda_{s}^{2}}-\left.\frac{\lambda_{n}}{\lambda_{s}} \frac{1}{2-\beta} \frac{d \omega_{n}^{x}}{d \lambda_{n}}\right|_{\lambda}<0 .
$$

As we know from the first part of the proof that $d \omega_{n}^{x} /\left.d \lambda_{n}\right|_{\lambda}>0$, it follows that $d \omega_{s}^{x} /\left.d \lambda_{n}\right|_{\lambda}<0$. This verifies that the South (at an interior solution) also increases IPR enforcement if its relative market size increases.

3. Consider now the steady-state growth rate in equilibrium:

$$
g=\frac{\beta P\left(\lambda_{n} \omega_{n}^{x}+\lambda_{s} \omega_{s}^{x}\right)}{2(1-\beta) \lambda \Delta} .
$$

Inserting $\omega_{n}^{x}$ as given by (A.5), inserting $\omega_{s}^{x}$, and substituting $\lambda-\lambda_{n}$ for $\lambda_{s}$, we obtain for the derivative with respect to $\lambda_{n}$ given, $d g /\left.d \lambda_{n}\right|_{\lambda}=0$.

\section{A.7. PROOF OF PROPOSITION 7}

The proof first shows that there is a unique solution to the North's optimization problem. Then we show that the desired harmonized enforcement level $\omega_{n}^{h}$ is strictly concave in $\Delta$ by verifying that the second derivative is negative. The derivative of $\omega_{n}^{h}$ with respect to $\Delta$ is always positive if the condition given in item (i) of Proposition 7 is satisfied. Otherwise the derivative will change its sign for higher values of $\Delta$, implying an inverted U-shaped relation between $\omega_{n}^{h}$ and $\Delta$. This verifies item (ii) of Proposition 7. With respect to item (iii), we first show that $\omega_{n}^{h}$ increases (decreases) with its relative effective market size if $\omega_{n}^{h}<(>) \omega_{s}^{h}$. Using the properties of $\omega_{n}^{h}$ and $\omega_{s}^{h}$ on the relevant interval of $\Delta$, we show that there exists a unique $\bar{\Delta}$ such that $\omega_{n}^{h}>(<) \omega_{s}^{h}$ if and only if $\Delta>(<) \bar{\Delta}$. This proves item (iii) of Proposition 7. The detailed formal proof is provided in the working paper version [Schäfer and Schneider (2013)].

\section{A.8. PROOF OF PROPOSITION 8}

The proof of Proposition 8 follows directly from the last part of the proof of Proposition 7, where we have shown that $\omega_{n}^{h}$ and $\omega_{s}^{h}$ possess a unique intersection where both $\omega_{n}^{h}$ and $\omega_{s}^{h}$ are greater than zero. $\bar{\Delta}$ is the level of $\Delta$ at this intersection. It follows further from the proof of Proposition 7 that $\omega_{n}^{h}<\omega_{s}^{h}$ if $\Delta<\bar{\Delta}$ and $\omega_{n}^{h}>\omega_{s}^{h}$ if $\Delta>\bar{\Delta}$. 